\title{
Por que a recuperação tem sido a mais lenta de nossa história?*
}

Why the recovery has been the slowest in our history?

\author{
Manoel Carlos Pires ${ }^{\dagger}$ \\ Bráulio Borges ${ }^{\ddagger}$ \\ Gilberto Borça Jr. ${ }^{\S}$
}

\begin{abstract}
Resumo
A recuperação econômica brasileira, que se seguiu à recessão de 2014-16, tem sido a mais lenta da história. $O$ baixo crescimento corrente ameaça o crescimento futuro reduzindo a perda de produtividade de trabalhadores que se ausentam por tempo elevado do mercado de trabalho e pela redução do estoque de capital da economia no que é conhecido como efeito histerese. $O$ quadro econômico que emerge da recessão é de elevada capacidade ociosa, inflação abaixo da meta e que pode ser compensado por taxas de juros menores. Com efeito, uma política monetária flexível além de oferecer estímulos monetários importantes para a recuperação também permite aumento dos investimentos públicos e abre espaço para outros itens da agenda de política econômica que possam aumentar seus efeitos.
\end{abstract}

Palavras-Chave: Histerese; Política monetária; Taxa de juros.

\begin{abstract}
Brazilian economic recovery that emerged from the 2014-16 recession is the slowest in history. Current low growth threats future growth reducing labor's productivity and capital stock, which is widely known as hysteresis effect. Brazil has a large idleness, inflation below the target and both must result in lower interest rate. Monetary stimulus will improve economic activity and create space for fiscal policy and other themes of economic policy debate.
\end{abstract}

Keywords: Hysteresis; Monetary policy; Interest rates.

JEL Classification: E32; E43; H60.

\footnotetext{
* Este artigo é uma versão atualizada do texto publicado no Blog do Ibre, disponível em $<$ https://blogdoibre.fgv.br/posts/por-que-recuperacao-tem-sido-mais-lenta-de-nossa-historia>

+ Pesquisador Associado do IBRE/FGV e Pesquisador colaborador da UnB. E-mail: mccpires@hotmail.com.

* Pesquisador Associado do IBRE/FGV e Economista Chefe da LCA Consultores. E-mail: braulioborges@hotmail.com.

$\checkmark$ Economista do BNDES. E-mail: gilbe@bndes.gov.br
}

BRAZILIAN KEYNESIAN REVIEW, 5(1), p.174-202, $1^{\text {st }}$ Semester/2019 


\section{Introdução}

A atual crise econômica brasileira não encontra paralelo na história documentada do país. Depois de dois anos consecutivos, 2015 e 2016, de forte contração do PIB, e outros dois, 2017 e 2018, de baixo crescimento, a economia encontra-se praticamente estagnada e flertando com a volta da recessão neste ano de 2019.

Mesmo que se ignore o forte recuo acumulado do PIB no biênio 2015/16 (de $-6,7 \%$ ), ainda assim, o crescimento de apenas 1,1\% em 2018 (ritmo semelhante ao que será observado no triênio 2017-19) colocou a economia brasileira apenas na $40^{\text {a }}$ posição em um ranking de desempenho do PIB englobando 42 países, segundo levantamento realizado pela consultoria privada Austin Rating. Somente Itália $(0,8 \%)$ e Japão $(0,7 \%)$ tiveram taxas de crescimento inferiores à da economia brasileira em 2018. Essa performance sofrível, que em termos per capita representa literalmente uma estagnação, coloca o país na trajetória mais lenta de recuperação que se seguiu a uma recessão (ao menos desde o final do século XIX).

As consequências econômicas e sociais da lenta recuperação da economia brasileira não podem ser minimizadas. Não somente pelos impactos óbvios que esse quadro vem trazendo em termos do bem-estar da sociedade nos últimos anos, mas também pelas possíveis consequências mais duradouras para o futuro - não somente econômicas, mas também políticas.

O impacto das oscilações cíclicas da atividade sobre os níveis de médio e longo prazo dos principais agregados macroeconômicos (como o PIB per capita) é um fenômeno que foi denominado pela academia como "histerese" - palavra que deriva do grego e significa "retardo", tendo sido originalmente utilizada na Física para descrever a tendência de um sistema de conservar suas propriedades na ausência de um novo estímulo. No campo da economia, o tema surgiu primeiramente com o trabalho de Phelps (1972) e, posteriormente, por Blanchard e Summers (1986), tendo ganhado atenção redobrada mais recentemente por conta dos desdobramentos da grande crise financeira de 2008/09.

São várias as maneiras pelas quais a histerese econômica se manifesta, mas a principal delas parece estar associada ao mercado de trabalho, mais especificamente ao processo de acumulação de capital humano pelos trabalhadores ao longo da vida laboral. Com efeito, quando a taxa de desemprego se situa em patamar atipicamente elevado (isto é, acima de níveis "neutros") e por muito tempo, maior tende a ser o ajuste e o conformismo com padrões de vida mais 
baixos, além dessa situação aumentar a incidência de distúrbios mentais associados a sentimentos de insegurança e ansiedade (inclusive para aqueles que continuam ocupados). Várias habilidades específicas adquiridas no ambiente de trabalho acabam sendo corroídas pelo chamado desemprego de longa duração. Quando, em algum momento, a economia finalmente volta a demandar mais mão-de-obra, uma quantidade expressiva de pessoas pode não se encontrar mais em condições de inserção no mercado ou o fazem em condições muito desfavoráveis, isto é, em posições de baixa produtividade ou na economia informal ${ }^{1}$.

As evidências empíricas mostram que o efeito histerese é bastante relevante. Khan (2010) encontrou evidências de que existem grandes diferenciais de salários que perduram por bastante tempo a depender do momento do ciclo econômico em que um trabalhador entrou no mercado de trabalho. Em outras palavras, se os trabalhadores entram no mercado de trabalho quando a economia está em recessão, seus salários são mais baixos do que aqueles que entram em condições mais favoráveis e essas diferenças duram por bastante tempo. Dessa forma, menores são as oportunidades, menor é o acúmulo de experiência ao longo da vida laboral, menor é a produtividade média da economia no longo prazo.

Vale notar que, em alguns países, observou-se que a recuperação econômica após uma recessão não veio acompanhada, ao menos em um primeiro momento, de aumento expressivo do nível de emprego, sobretudo daqueles com maior qualidade. Para descrever essas situações, cunhou-se o termo jobless recovery. Contudo, o desempenho brasileiro, em função da lenta retomada da atividade, coloca o país um passo atrás desse tipo de debate.

Outra consequência importante relacionada aos efeitos de longo prazo da lenta recuperação está no investimento em ativos fixos e, portanto, na quantidade e qualidade do estoque de capital da economia (atributo que depende, dentre outras coisas, do grau de obsolescência desse estoque). $O$ investimento tende a se elevar quando há demanda crescente, corrente e esperada, por novos produtos (que pode ser atendida mediante aumento das importações ou da expansão da oferta doméstica), abertura ou criação de novos mercados, inovações, condições financeiras mais favoráveis e baixo nível de incerteza. É inegável que vários desses fatores estão atuando como ventos contrários a uma recuperação mais firme do

\footnotetext{
${ }^{1}$ No Relatório Trimestral de Inflação de junho de 2019, o BCB apresentou um box intitulado "Duração da Desocupação e Inflação", no qual concluiu que desempregados de longa duração (isto é, não ocupados há mais de 2 anos) acabam sendo recolocados no mercado de trabalho em setores informais e com remunerações mais baixa relativamente aos desempregados de curta duração (abaixo de 1 ano).
} 
investimento na economia brasileira nos últimos anos, mas pouco destaque tem sido dado à letargia da demanda, que sofre com uma economia que não mostra sinais inequívocos de reação (Braga e Lara, 2019). O outro lado da moeda dessa deficiência crônica de demanda é justamente o excesso de ociosidade dos fatores de produção - tanto no mercado de trabalho como do capital - os quais atuam, efetivamente, como fatores limitantes de novos investimentos em ativos fixos.

Várias hipóteses têm sido levantadas para tentar explicar o porquê da "década frustrante" para a economia brasileira. Embora haja muita controvérsia dentre os analistas sobre quanto disso seria uma consequência direta e indireta de políticas ruins de períodos anteriores e/ou mudanças da conjuntura internacional ou ainda de choques não antecipados -, formou-se um consenso razoável de que mudanças/reformas, no sentido de uma maior racionalização da política econômica doméstica, pareciam ser necessárias. De fato, várias reformas vêm sendo implementadas desde 2015, envolvendo um maior controle das despesas públicas, a redução do escopo do crédito público, reformas da previdência e tributária, abertura comercial, dentre outras.

Todas essas iniciativas, em algum grau, parecem adequadas e necessárias (ainda que não se possa ignorar os detalhes e mesmo o sequenciamento de algumas dessas reformas). Mas todas elas parecem atuar muito mais no sentido de evitar uma nova "década frustrante", ao preparar terreno para um ritmo médio de expansão econômica mais elevado do que nas últimas quatro décadas. Contudo, praticamente ignoram aquilo que parece ser mais o fundamental no curto prazo, em especial quando se leva em conta o risco associado à histerese: afinal, por que a retomada cíclica da economia brasileira tem sido atipicamente fraca no ciclo atual, mesmo quando comparada com outros episódios tão severos, prolongados e conturbados vividos por nós mesmos, como aqueles de 1981-83 e 1989-92?

Este artigo traz à tona essa questão buscando identificar algumas razões que ajudam a explicar o desempenho cíclico muito aquém do esperado da economia brasileira desde 2017. Além desta introdução, este texto está dividido em três seções. A primeira faz um dimensionamento da crise brasileira em termos de padrões históricos, além de comparações com as recessões de algumas das principais economias avançadas no pós-crise de 2008. A segunda se dedica a uma análise mais pormenorizada da posição cíclica da economia brasileira, buscando avaliar o comportamento de oferta e demanda agregadas e se a política econômica respondeu de forma adequada a esse quadro. A última seção traz algumas 
considerações finais, apresentado algumas sugestões de prescrição de política econômica.

\section{Dimensionando a crise brasileira}

De acordo com a datação do CODACE - Comitê de Datação dos Ciclos Econômicos da FGV -, a economia brasileira vivenciou nove episódios recessivos desde $1980^{2}$. Isso significa que, em quase quatro décadas, o Brasil teve, em média, uma contração econômica a cada quatro anos. De fato, conforme já abordado, a recessão de 2015 e 2016 foi bastante pronunciada. Uma forma de verificar isso é avaliar sua dimensão comparativamente as outras experiências.

Borça Jr., Barboza e Furtado (2019) mostraram que, historicamente, as recessões brasileiras são breves (acontecem por períodos curtos), pouco profundas (com perdas relativamente modestas de PIB), e com recuperações rápidas e consistentes. Tomando como referência a média simples dos nove episódios recessivos desde 1980 (incluindo o ciclo mais recente), os ciclos econômicos brasileiros demoraram menos de dois anos (exatamente 7 trimestres) para se completarem. Isto é, em um período inferior a 24 meses, a atividade econômica se contrai, atingindo seu vale e, posteriormente, se recupera integralmente, retomando os mesmos níveis de produção observando no período imediatamente anterior ao início da recaída recessiva.

O Gráfico 1 compara a trajetória do PIB total em todas recessões brasileiras desde 1980, com especial destaque para a média simples dos nove episódios e para os três episódios mais longevos e profundos: i) 1981-83; ii) 1989-92; e iii) 2014-16.

A recessão de 1981-83, além de ter sido intensa e rápida, de maneira diferente da média das contrações brasileiras, foi caracterizada por uma recuperação em formato de "W", também denominada na literatura como "double dip", na qual a economia inicia uma trajetória de retomada e, posteriormente, volta a se contrair, antes de finalmente retomar para os níveis prévios à recessão. $\bigcirc$ início dos anos de 1980 foi um período bastante conturbado. As condições de financiamento externo da economia brasileira tiveram uma mudança abrupta em função da expressiva elevação das taxas de juros nos EUA, levando boa parte das economias da América Latina (inclusive o Brasil) a decretarem moratórias de suas dívidas externas. É importante notar que o surto de forte crescimento associado ao

2 Para maiores detalhes da datação dos ciclos econômicos pelo CODACE, ver: https://portalibre.fgv.br/data/files/F3/C1/F8/E8/A18F66108DDC4E66CA18B7A8/Comite\%20de\%2 0Data_o\%20de\%20Ciclos\%20Econ_micos\%20-

\%20Comunicado\%20de\%2030_10_2017\%20_1_.pdf 
Plano Cruzado, em 1986, impactou a trajetória do PIB apresentada pela linha azul na figura acima somente nos três trimestres finais $(T+18$ a $T+20)$.

Gráfico 1. Padrão de Evolução do PIB brasileiro em recessões desde 1980

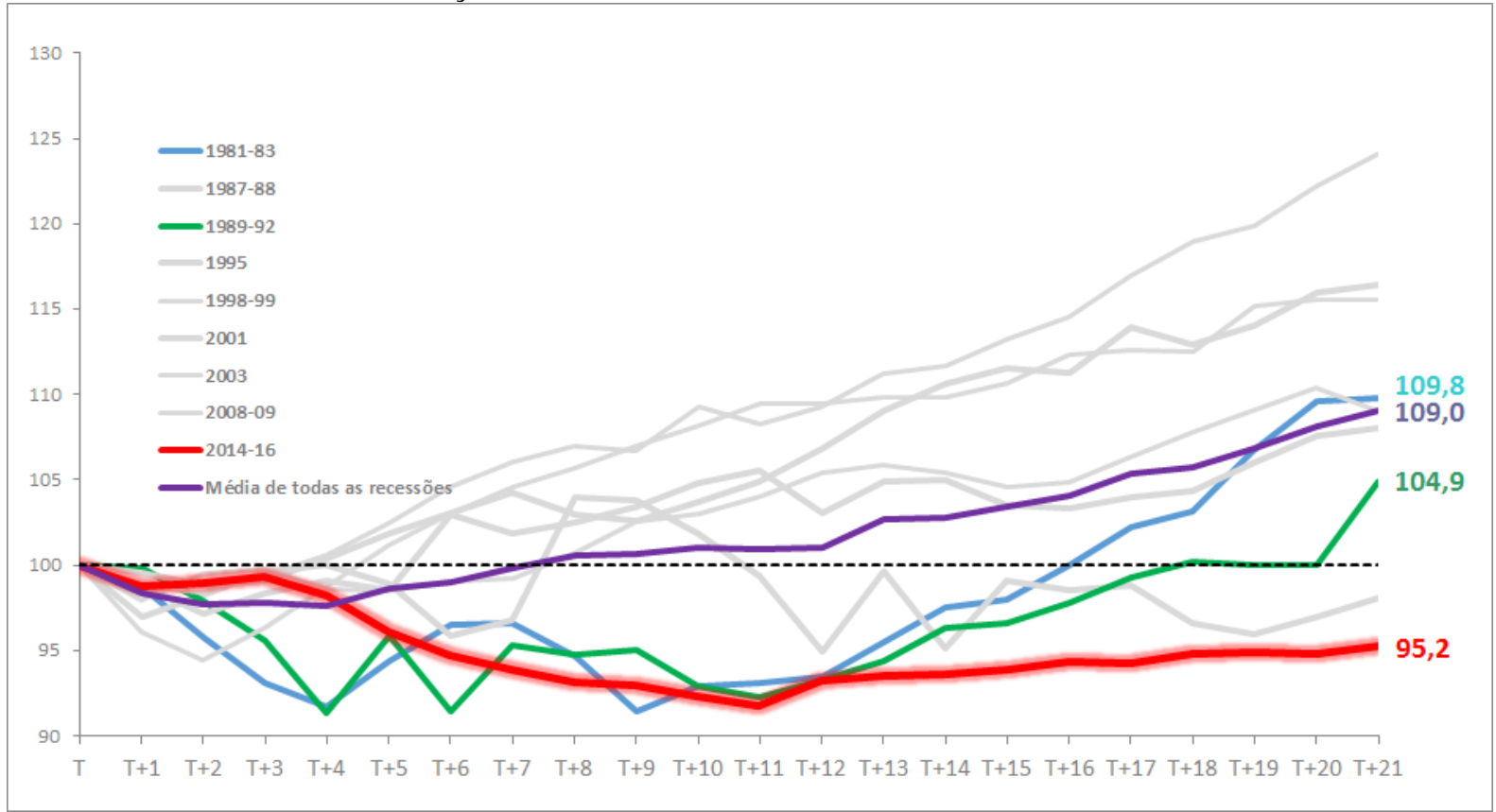

Fonte: Elaboração própria a partir de dados do Ipeadata e do IBGE. Nota: pico imediatamente anterior ao início da recessão, $T=100$, série com aj. sazonal.

O episódio recessivo de 1989-92 também foi caracterizado por uma queda rápida e forte do nível de atividade. A recuperação, entretanto, foi bastante irregular, com dois movimentos de aceleração e posterior contração. Tal processo esteve relacionado à implementação do Plano Collor no início de 1990, em que os agentes econômicos foram submetidos a uma forte contração de liquidez. Vale assinalar, no caso deste episódio, que a forte aceleração do crescimento do PIB brasileiro observada após a implementação do Plano Real, em meados de 1994, não aparece na figura acima, tendo ocorrido alguns trimestres além do horizonte apresentado no gráfico.

Por sua vez, o último período recessivo, entre 2014-16, possui características bem peculiares. Embora não tenha sido a crise com a queda mais rápida do PIB, considerando sua trajetória do pico até o vale (na crise de 2008-09, por exemplo, a economia se contraiu mais rápido até atingir seu ponto mais baixo), ela foi a crise mais severa em termos de longevidade de contração da atividade econômica. O PIB se retraiu de maneira praticamente ininterrupta por 11 trimestres consecutivos, isto é, por quase 3 anos. A perda acumulada de produto também foi significativa, atingindo mais de $8,0 \%$. 
Contudo, ainda no que tange à recessão de 2014-16, o que mais chama atenção é sua trajetória de recuperação, que é atipicamente lenta. Passados 21 trimestres, ou seja, mais de 5 anos, a economia ainda se encontra 4,8\% abaixo de seus patamares pré-recessão. Caso se leve em conta o fato de que na média das nove recessões desde 1980, transcorrido tal intervalo de tempo, o PIB já estaria cerca de 9,0\% acima de seu patamar pré-crise, o atual processo de recuperação mostra uma economia ainda $12,7 \%$ abaixo de seu padrão histórico de retomada. Até mesmo nas recessões de 1981-83 e 1989-92, comparáveis ao ciclo de 2014/16, a economia já havia retomado o nível anterior ao tombo entre 2 e 3 anos depois de atingido o "fundo do poço" (e antes de que "choques" positivos, como o Plano Cruzado e o Real, acelerassem ainda mais o crescimento econômico).

O Gráfico 2 compara a dinâmica da recuperação brasileira no ciclo mais recente com as trajetórias observadas nos países da periferia da Zona do Euro (PIGS - Portugal, Itália, Grécia e Espanha) no começo da década atual.

Gráfico 2. Comparação da Recessão/Recuperação atual do Brasil com a dos PIGS

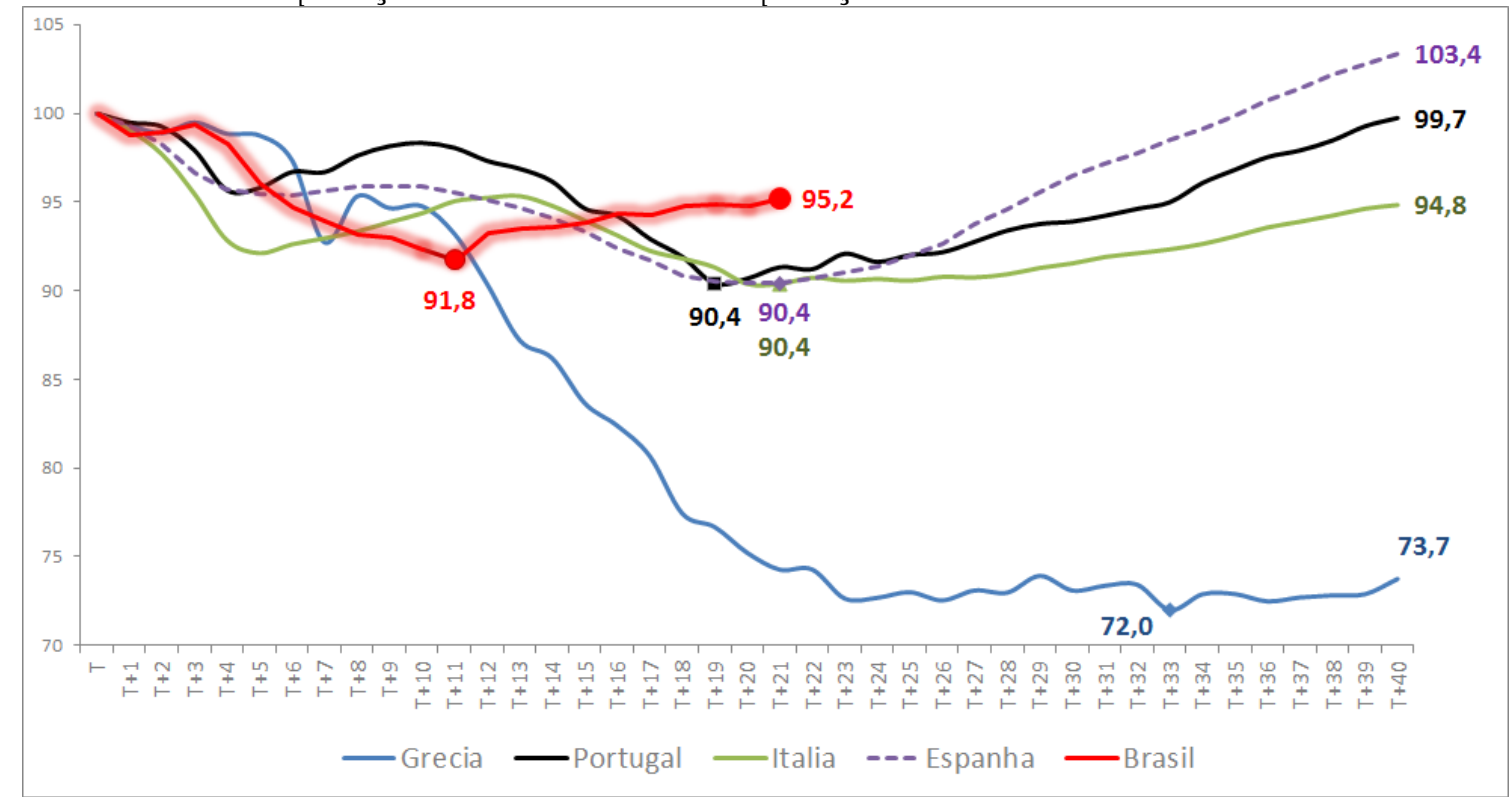

Fonte: Elaboração própria a partir de dados da Bloomberg. Nota: pico imediatamente anterior ao início da recessão, $T=100$, série com aj. sazonal.

Chamam a atenção quatro pontos. O primeiro deles diz respeito à velocidade com a qual a economia brasileira se contraiu até seu vale (isto é, em 11 trimestres), que foi mais intensa do que a desse conjunto de países no mesmo intervalo de tempo.

O segundo é que a magnitude da recessão ocorrida no Brasil - ou seja, sua variação do pico ao vale - é razoavelmente semelhante aos episódios recessivos 
recentes ocorridos em Portugal, Itália e Espanha, sendo menos intensa do que no caso grego.

O terceiro é que, transcorridos mais de 5 anos (21 trimestres), a trajetória de recuperação brasileira é apenas um pouco melhor do que as ocorridas em Portugal, Espanha e Itália.

E, por fim, após 10 anos (40 trimestres), apenas Espanha e Portugal recuperaram seus níveis de produção anteriores à recessão. A Itália encontrava-se ainda $5 \%$ abaixo e, na Grécia, o colapso da economia parece permanente, com o nível do PIB mais de $25 \%$ abaixo dos patamares prévios à crise.

Colocar a recessão brasileira de 2014-16 e sua lenta recuperação em perspectiva, comparando-a aos episódios ocorridos nos países da periferia da Zona do Euro, enseja uma reflexão interessante sobre a resposta de política econômica. Tais economias são integrantes da Zona do Euro e, portanto, não tinham total autonomia para utilização dos instrumentos tradicionais de política econômica como, por exemplo, monetário, fiscal e cambial - que a economia brasileira em tese possui para gerenciar os ciclos econômicos. Em outras palavras, as ferramentas domésticas de enfrentamento da crise eram bem mais restritas.

De fato, a união monetária europeia, embora tenha gerado benefícios inequívocos para tais economias - como a redução do custo de financiamento desses países em função da convergência das taxas de juros de mercado para os níveis germânicos e franceses - diminuiu significativamente os graus de liberdade para as políticas econômicas domésticas no momento da crise.

Nesse caso, a estratégia de enfrentamento da crise foi realizada a partir de um forte ajustamento da absorção doméstica (sobretudo de gastos públicos), o qual contribuiu para uma profunda recessão, culminando em intensa deflação de preços e salários nessas economias. $\bigcirc$ objetivo central era a recuperação da competitividade externa via desvalorização "interna" da taxa de câmbio real e efetiva em um contexto de taxa nominal de câmbio única para o bloco como um todo e, portanto, "exógena" para cada um dos países, sobretudo para os menores. No entanto, a consequência mostrou-se dolorosa para o nível de atividade econômica, tornando a crise intensa e longa na periferia da Zona do Euro.

Tais efeitos poderiam ter sido suavizados e/ou compartilhados caso os países com posição superavitária no saldo do balanço de pagamentos em transações correntes na Zona do Euro (notadamente a Alemanha) tivessem realizado políticas compensatórias de estímulos à demanda agregada doméstica, como, por exemplo, 
aumento de gastos públicos. Uma maior coordenação intra-regional do ajuste macroeconômico certamente teria contribuído para amenizar os impactos contracionistas de emprego e renda nos países da periferia da Zona do Euro, tornando o processo recessivo mais brando.

Outra comparação interessante a ser realizada é entre a dinâmica da atual recuperação brasileira e aquela ocorrida na economia americana após a crise de 2008 (Gráfico 3). Nota-se que a economia norte-americana, epicentro da grande crise financeira internacional de 2008, teve uma perda relativamente modesta e rápida de PIB. Em 6 trimestres (um ano e meio), a economia atingiu seu ponto de vale da recessão, com perda acumulada de produto da ordem de $4,0 \%$. Passados mais 6 trimestres (mais um ano e meio), os níveis pré-crise de produção já haviam sido restabelecidos. Em outras palavras, o ciclo econômico norte-americano, advindo da maior crise financeira global desde a Grande Depressão dos anos 1930, durou aproximadamente 3 anos - em que pese o fato de que a bolha imobiliária observada entre meados da década de 2000 e 2007 tenha gerado uma expressiva má-alocação (misallocation) de capital naquela economia, que levou quase uma década para ser completamente "digerida".

Gráfico 3. Comparação da Recessão/Recuperação atual do Brasil com a dos EUA

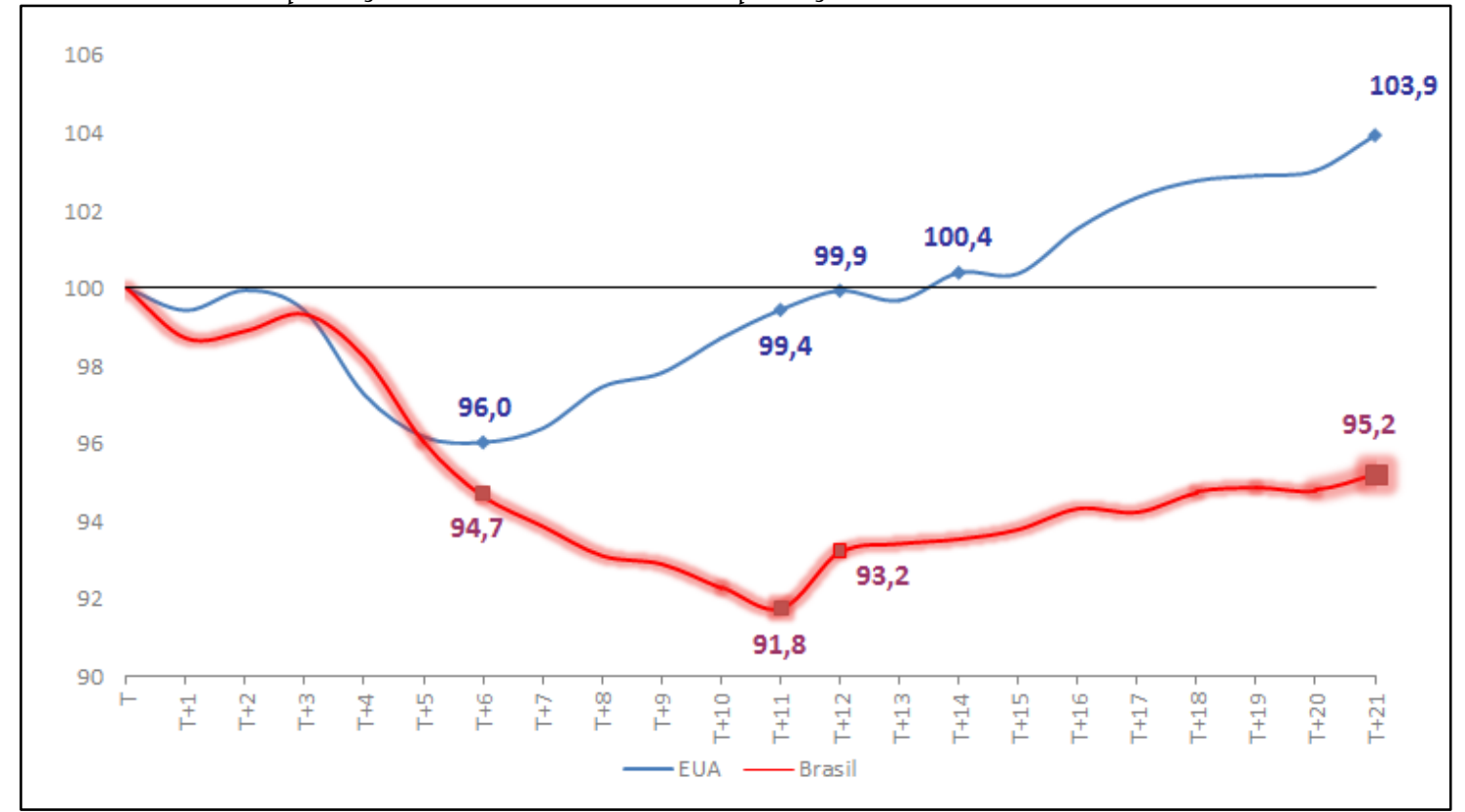

Fonte: Bloomberg e IBGE. Nota: pico imediatamente anterior ao início da recessão, $\mathrm{T}=100$, série com aj. Sazonal.

O ciclo recessivo recente brasileiro, por outro lado, foi muito mais profundo do que o dos EUA, com a perda acumulada total de PIB (até o vale) atingindo mais do que o dobro da norte-americana (4,0\% contra $8,2 \%)$. O tempo que o Brasil 
demorou até atingir o vale do processo recessivo (11 trimestres) foi quase o mesmo tempo em que a economia americana levou para retomar seu nível de produção prévio à recessão.

Algo relevante a ser notado é que os EUA, diferentemente dos países da periferia da Zona do Euro, utilizaram uma vasta gama de instrumentos de combate à crise, desde aqueles mais convencionais de políticas fiscal e, sobretudo, monetária - como a redução da taxa básica de juros até seu limite inferior (zero lower bound) - até os não-convencionais, como, por exemplo, os programas de afrouxamento quantitativo monetário. Tal expansão de liquidez foi viabilizada por compras massivas, pela autoridade monetária, de títulos públicos de várias maturidades (afetando a curva de estrutura à termo de taxas de juros), bem como de títulos de dívida privados, em particular de dívidas hipotecárias ${ }^{3}$. Os ativos no balanço do Federal Reserve, Banco Central norte-americano, elevaram-se de menos de US\$ 1 trilhão em 2008, para mais de US\$ 4,5 trilhões em 2015.

Em termos comparativos, enquanto a economia americana já havia retomado seus níveis de produção prévios em 3 anos, transcorrido esse mesmo intervalo de tempo (12 trimestres), a economia brasileira permanecia quase $7 \%$ abaixo de seu pico anterior de produção. Além disso, passados 21 trimestres, enquanto o PIB brasileiro ainda se encontra 4,8\% abaixo do pico pré-recessão, a economia norte-americana, nesse mesmo período, já havia superado em 3,9\% seu nível máximo de PIB anterior.

Com efeito, pode-se concluir que a última crise brasileira, além de ter sido de grande magnitude (tão severa e prolongada quanto aquelas de 1981-83 e 198992, ao longo do período de queda), é a mais lenta em termos de recuperação após o "fundo do poço" (ao menos desde 1980). Comparando-a com as contrações mais recentes ocorridas tanto na periferia da Zona do Euro como nos EUA, associadas em boa medida ao colapso financeiro global iniciado em 2008, nota-se que a dinâmica de retomada do Brasil guarda maior semelhança com a dos países da periferia da Zona do Euro (exceção feita à Grécia), os quais tinham restrições na utilização autônoma (isto é, doméstica, "taylor-made") dos instrumentos de política econômica de gestão do ciclo econômico.

Uma questão adicional que emerge quando se analisa o atual ciclo econômico brasileiro é saber quando a economia recuperará seus níveis de

${ }^{3}$ Para efetividade dos programas de afrouxamento quantitativo nas taxas de juros de longo prazo, ver Williams (2013). 
produção anteriores à recessão. $\bigcirc$ Gráfico 4 mostra duas possíveis trajetórias. A primeira contendo a mediana das expectativas de mercado coletadas pelo Banco Central do Brasil (BCB) no âmbito do Boletim Focus em meados de julho de 2019 (linha pontilhada ${ }^{4}$. E a segunda que adota como hipótese a extrapolação da taxa de crescimento da economia brasileira ao longo dos últimos dois anos, que foi de $+1,1 \%$.

Gráfico 4. Trajetória de Recuperação do Brasil - Projeções de Mercado vs Ritmo Atual

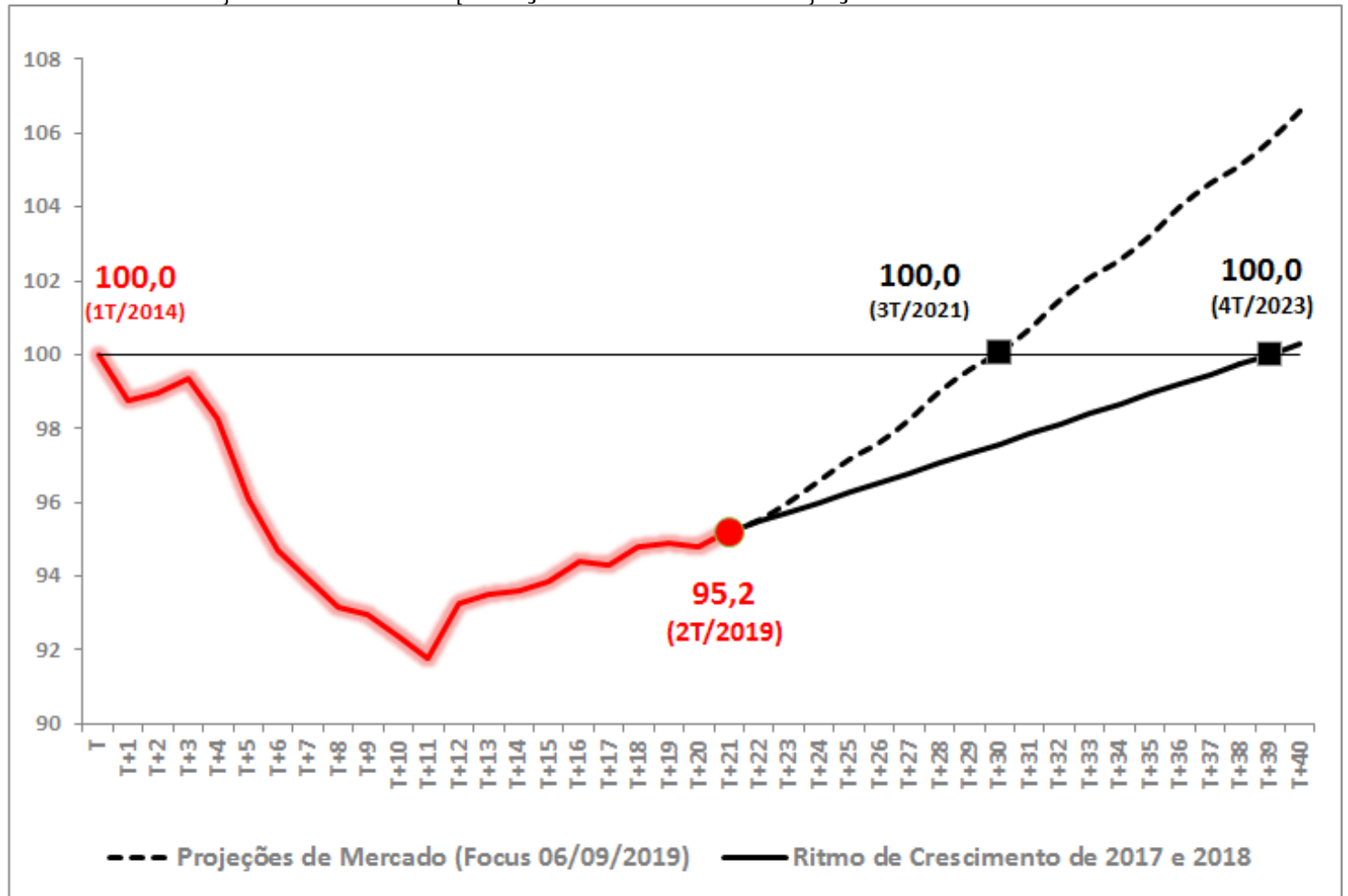

Fonte: Elaboração própria a partir dados do IBGE e do Boletim Focus BCB. Nota: pico imediatamente anterior ao início da recessão, $\mathrm{T}=100$, série com aj. sazonal.

Com a trajetória esperada pelo mercado, a economia brasileira se recuperaria integralmente apenas no 3T/2021, isto é, 30 trimestres depois (7,5 anos) após o início da recessão. Por outro lado, caso o ritmo de recuperação da atividade permaneça igual ao dos últimos dois anos, a retomada dos níveis de produção prérecessão aconteceria apenas 39 trimestres depois (ou seja, em quase uma década), no 4T/2023.

Pastore et. al (2019) seguem argumentação semelhante, mas fazendo uma análise dos dados anuais de crescimento per capita brasileiro desde o início do século XX. Por tal métrica, os autores encontram 15 ciclos econômicos no Brasil e

${ }^{4}$ Equivale a um crescimento anual de 0,87\% em 2019, 2,07\% em 2020, e de 2,5\% nos anos subsequentes. 
avaliam que, com a deterioração recente das perspectivas de crescimento para 2019, a renda per capita brasileira permanecerá por 3 anos consecutivos praticamente estagnada e cerca de 8,0\% abaixo de seu pico prévio. Esse fenômeno pode ser caracterizado, na visão dos autores, como uma depressão.

Caso o país volte a crescer, a partir de 2020, a um ritmo de cerca de 2,0\% a.a., o PIB per capita retomaria o nível prévio à recessão apenas em 2026 (13 anos depois) $)^{5}$. Se o crescimento for mais acelerado, atingindo $2,5 \%$ a.a., a recuperação integral do PIB per capita aconteceria em 2024 (11 anos depois).

Por fim, de acordo com Montero (2019), tomando como base as atuais taxas de crescimento esperadas para o PIB e para a população brasileira em 2019 e 2020, o país vivenciará, desde o início do século XX, sua terceira década perdida, sendo que duas delas concentradas nos últimos 40 anos. $\bigcirc$ Gráfico 5 mostra a evolução da média móvel de 10 anos da taxa de variação do PIB per capita brasileiro desde 1900. As três décadas perdidas são: i) 1907-16, com queda da 0,35\% a.a. do PIB per capita; ii) 1981-1990, com contração de 0,46\% a.a.; e por fim, iii) 2011-2020, com variação nula ${ }^{6}$.

Gráfico 5. PIB per capita do Brasil, média móvel de 10 anos da taxa de variação, em $\%$

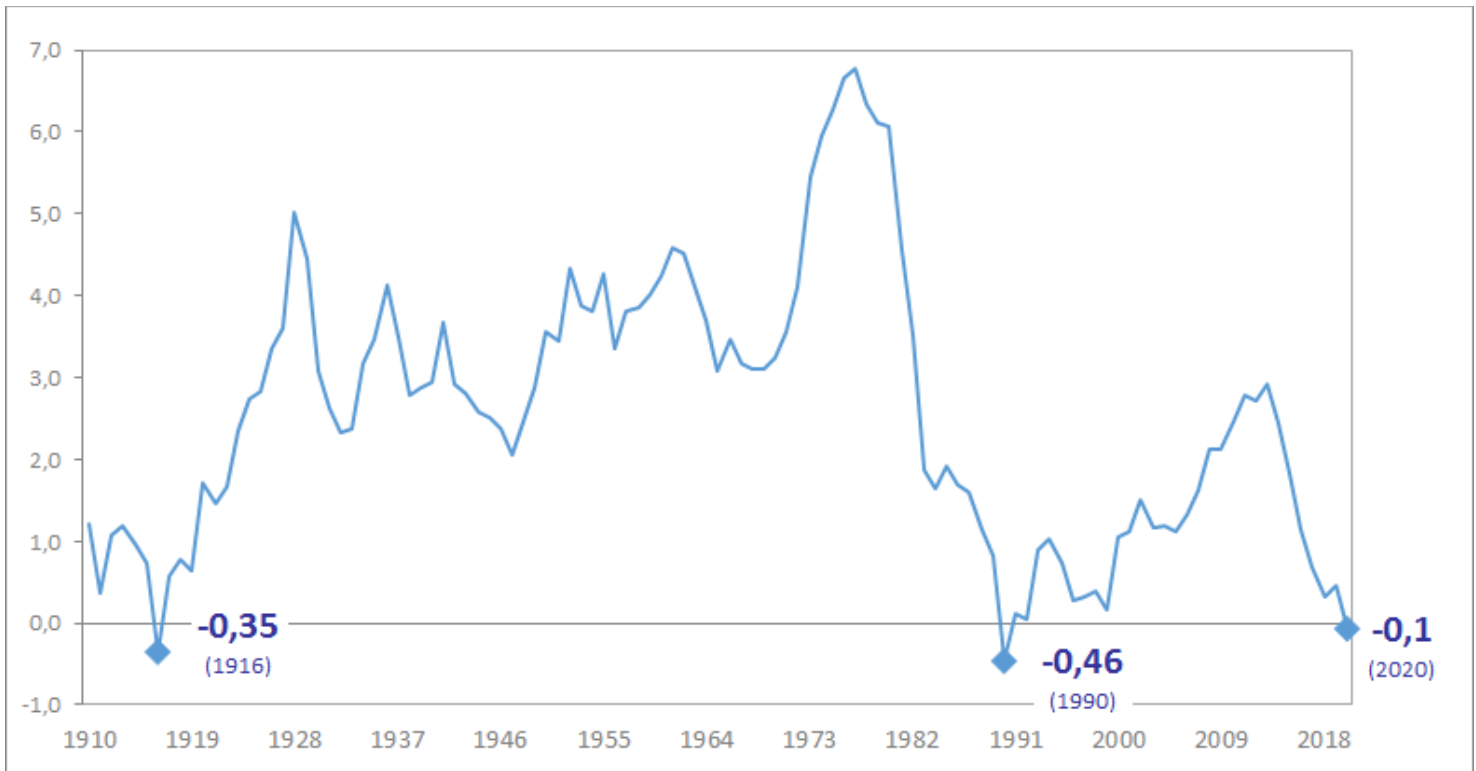

Fonte: Ipeadata.

\footnotetext{
${ }^{5}$ É importante mencionar que, quando a variável de análise passa a ser o PIB per capita, o pico prérecessão aconteceu em 2013.

6 Barboza (2019) classificou a década de 2011-20 como "década frustrada", na qual as taxas de crescimento da economia foram, sistematicamente, inferiores às projetadas.
} 
As perspectivas de retomada, por sua vez, estão sendo sucessivamente frustradas desde meados de 2016. Essa é uma constatação de extrema relevância, na medida em que sinaliza que, na visão dos agentes de mercado, a economia brasileira poderia ter acelerado significativamente seu crescimento a partir de 2017 - e sem gerar desequilíbrios inflacionários, já que as projeções também apontavam inflação em torno da meta.

Dessa maneira, por qualquer ótica que se analise o atual ciclo econômico brasileiro, seja em comparação com os outros episódios recessivos nacionais passados, seja relativamente a grandes crises recentes em outras economias, ou mesmo com relação à perspectiva futura, a situação é bastante preocupante.

Gráfico 6. PIB Brasil - projeções de consenso vs observado (var. \% anual)

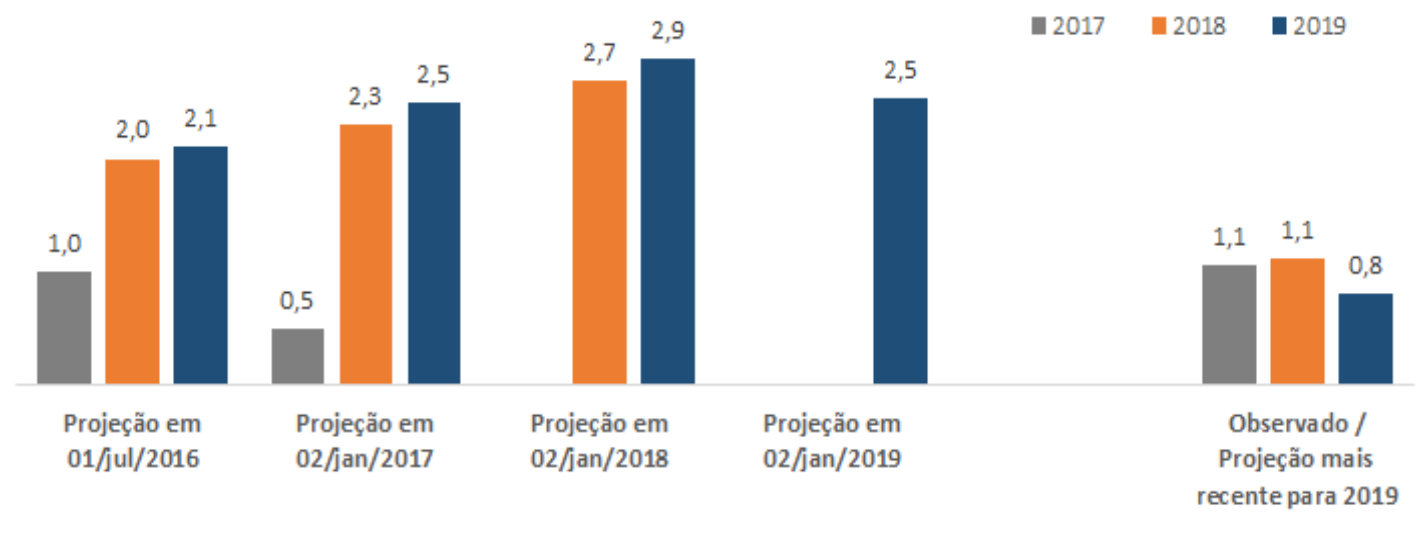

Fontes: Focus/BCB e IBGE.

\section{Por que a retomada atual tem sido atipicamente lenta?}

A resposta a esse questionamento passa longe de ser trivial. Mas um primeiro passo necessário para elucidar essa questão envolve avaliar se o crescimento lento dos últimos anos seria um "novo normal", sendo limitado por restrições agregadas pelo lado da oferta - na medida em que os investimentos em ativos fixos colapsaram desde meados de 2013 e que o período de bônus demográfico (em que o crescimento da População em Idade Ativa, PIA, é superior ao crescimento da população como um todo) ficou para trás, de acordo com as revisões demográficas mais recentes divulgadas pelo IBGE no final de $2018^{7}$.

Embora esses fatores - em conjunto com ganhos tendenciais de produtividade bem modestos observados na economia brasileira nas últimas décadas - apontem para uma taxa de crescimento mais baixa da capacidade de

\footnotetext{
${ }^{7}$ Ao final do 1T/2019, os investimentos - medidos pela Formação Bruta de Capital Fixo da economia - estavam 27\% abaixo dos níveis registrados no 1T/2014.
} 
oferta doméstica de bens e serviços nos últimos anos, o fato é que boa parte das estimativas de excesso de ociosidade da economia brasileira - aponta para uma economia operando bastante aquém do pleno-emprego dos fatores de produção nos últimos anos.

O Gráfico 7 apresenta média, mediana e desvios-padrão de 9 estimativas independentes de hiato do produto para a economia brasileira (três estimativas do IBRE/FGV; duas da LCA; duas da MCM; uma da IFI/Senado e uma do IPEA). Como pode ser notado, tanto a média como a mediana dessas estimativas indicam que, no 1T/2019, a economia brasileira estava operando em um nível aproximadamente $5,5 \%$ inferior ao potencial. Esse exercício também aponta que esse excesso de ociosidade pouco se alterou desde o final de 2016, quando o PIB brasileiro atingiu o "fundo do poço" no ciclo recessivo mais recente.

Gráfico 7. Medidas de hiato do produto no Brasil (em \%)

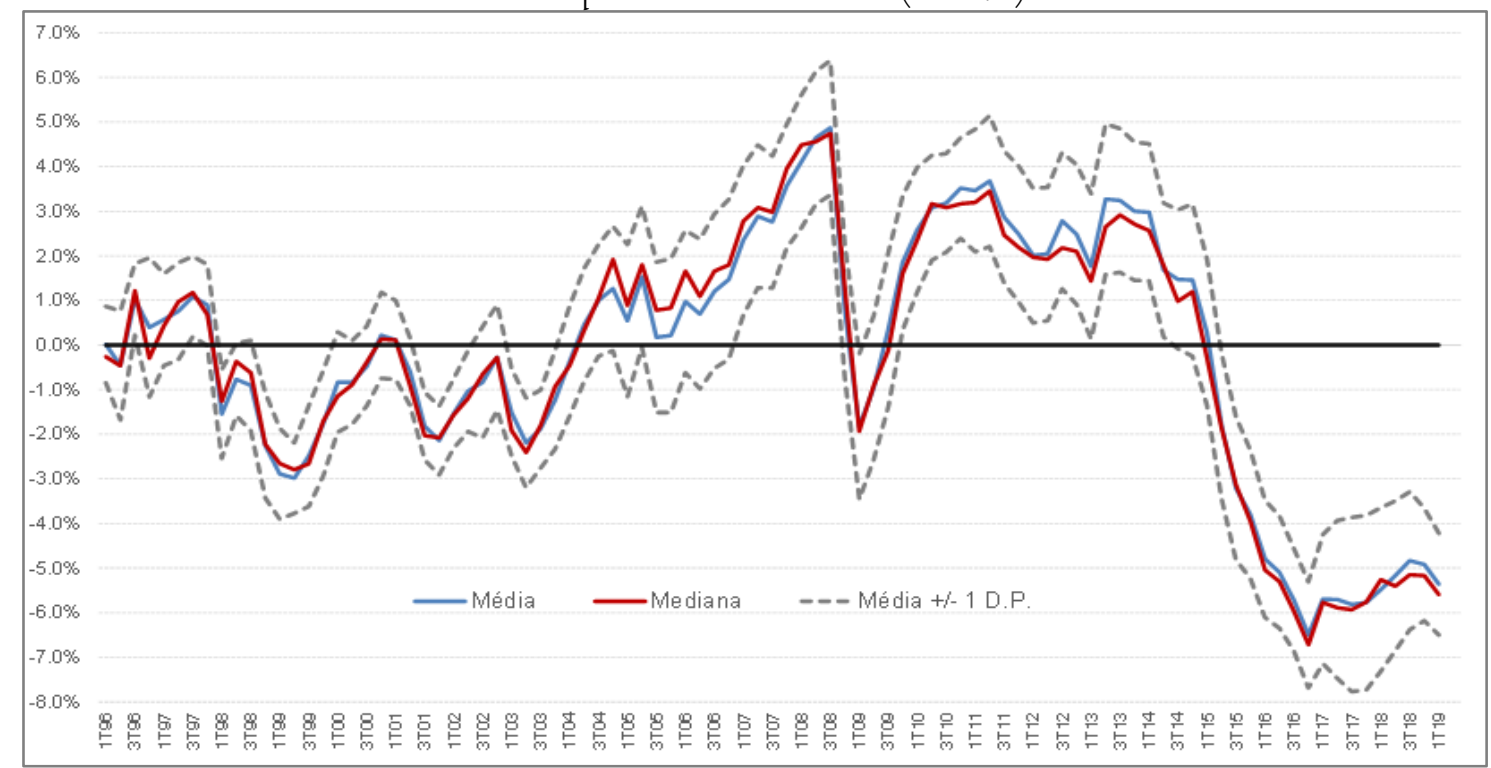

Fonte: LCA, MCM, IBRE/FGV, IFI/Senado e IPEA.

Essas medidas não contemplam as estimativas de outras entidades, tais como o FMI e a Secretaria de Política Econômica (SPE), ligada ao Ministério da Economia. Mas relatórios recentes de ambas as instituições reforçam o diagnóstico de um quadro de elevado excesso de ociosidade, ainda que numericamente apontem estimativas mais próximas do intervalo superior do Gráfico 7: a SPE, em abril deste ano, estimava um hiato negativo em cerca de 3,5\% no final de 2018; já o FMI, em relatório divulgado no final de julho de 2019, indicava um hiato em torno de $-4 \%$ neste ano de 2019.

O Gráfico 8 ajuda a compreender melhor essa questão de oferta vs. demanda agregadas e ociosidade da economia, ao apresentar os níveis absolutos do PIB 
efetivo e da estimativa do PIB potencial (neste último caso, obtida a partir da aplicação do hiato do produto médio apresentado na figura acima à série do PIB efetivo dessazonalizado). Como pode ser notado pela mudança de inclinação do PIB potencial, houve, de fato, uma forte desaceleração de seu ritmo de expansão (isto é, da expansão da capacidade de oferta doméstica de bens e serviços) nos últimos anos. Após variar cerca de $+2,9 \%$ a.a. em 1997-2013, ele variou $+0,8 \%$ a.a. em 2014-2018, tendo avançado apenas 0,4\% no ano passado. Ou seja: esses números não são incompatíveis a com a avaliação de que investimentos ruins realizados em períodos anteriores ("misallocation") ou sobreinvestimento em alguns setores antes de 2014 vêm pesando sobre a dinâmica do PIB potencial (como sugerem as taxas negativas da produtividade total dos fatores observadas nos últimos anos).

Contudo, a variação do PIB potencial não chegou a ser negativa em nenhum dos últimos anos, em claro contraste com o caso do PIB efetivo, que variou $-3,5 \%$ e -3,3\% em 2015-16, respectivamente.

Gráfico 8. PIB efetivo e potencial no Brasil, em R \$ bilhões constantes de 2016, com ajuste sazonal

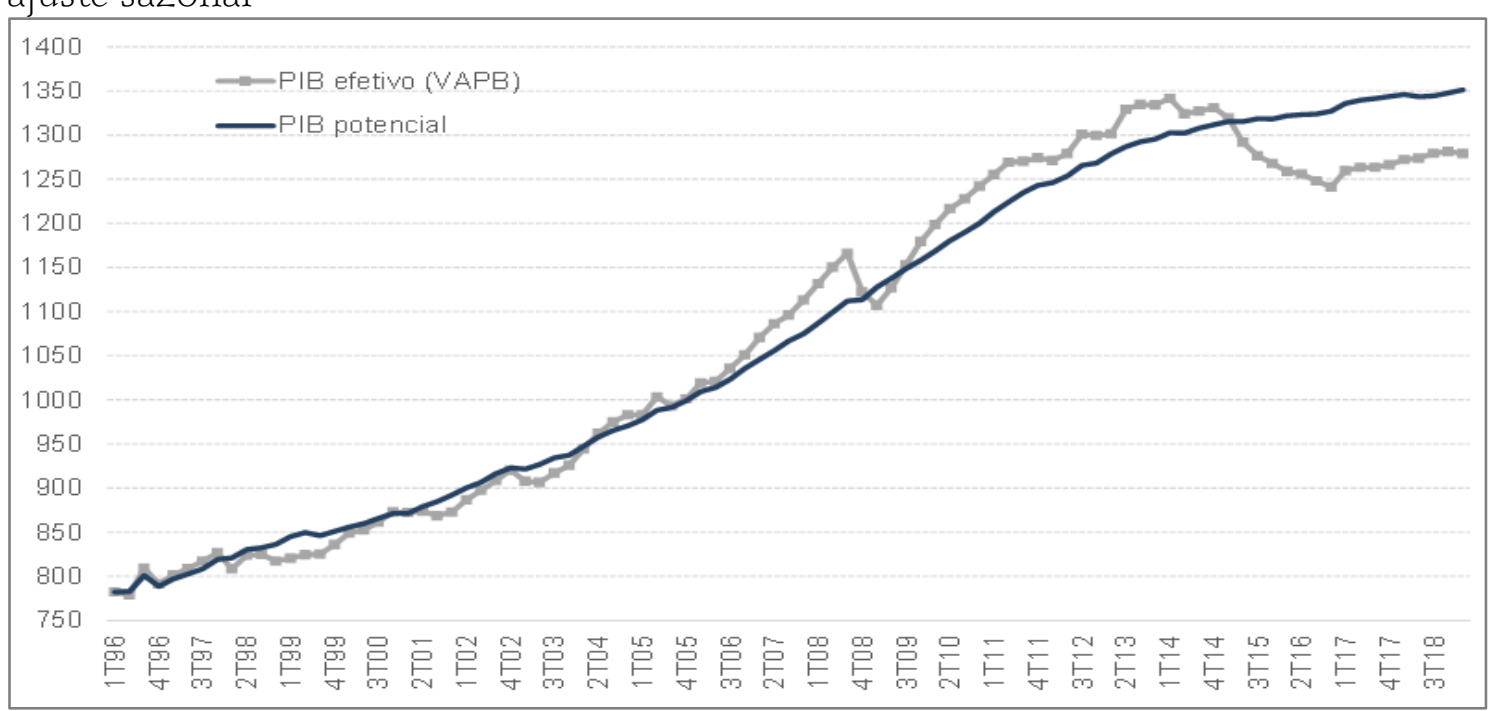

Fonte: IBGE, LCA, MCM, IBRE/FGV, IPEA e IF//Senado.

Com efeito, a recessão de 2014-16 gerou um excesso de ociosidade ao longo daquele período e, desde então, o crescimento do PIB efetivo não foi suficiente para consumir o excesso de ociosidade.

Uma forma alternativa de analisar essa questão, dado que o hiato do produto é uma variável cujo cálculo envolve algum nível de imprecisão (já que se trata de uma variável não-observável), pode ser feita a partir de sua manifestação prática na economia. Isso pode ser inferido a partir da observação do comportamento de 
algumas variáveis, como por exemplo, os indicadores de contas externas e a inflação.

No que tange à evolução das contas externas brasileiras, é possível perceber que o déficit em transações correntes tem sido muito baixo comparativamente ao seu padrão histórico e mesmo com base nas características mais estruturais da economia brasileira (regime de câmbio flutuante, passivo externo líquido negativo e baixa taxa de poupança doméstica).

Ademais, a diferença entre o saldo em conta corrente e o influxo de investimentos estrangeiros diretos no país - isto é, a necessidade de financiamento externo - tem se alargado nos últimos anos, denotando a existência de um espaço razoável para que a economia brasileira se acelere sem que isso implique algum tipo de desequilíbrio relevante no balanço de pagamentos.

Gráfico 9. Déficit em transações correntes e investimento direto no Brasil, em \% do PIB

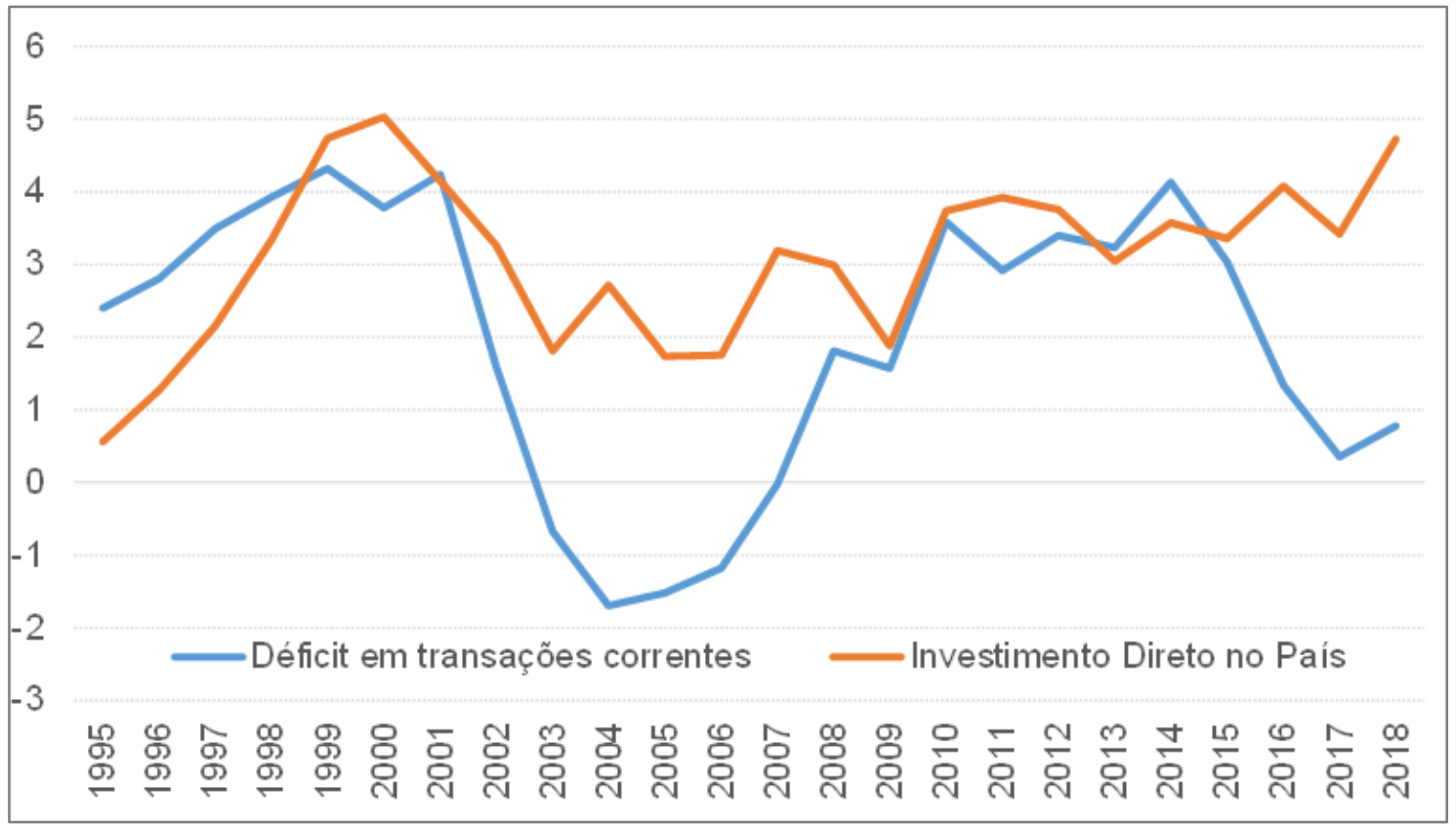

Fonte: $\mathrm{BCB}$ e Ipea.

Outra evidência vem do comportamento da inflação comparativamente às metas definidas pelo Conselho Monetário Nacional (CMN). O Gráfico 10 mostra que a inflação brasileira está correndo bastante abaixo da meta desde 2017 fenômeno que tende a se repetir neste ano de 2019, na medida em que as projeções de consenso mais recentes apontam para uma alta do IPCA em torno de 3,8\%, contra uma meta de 4,25\%. Há uma chance também de que a inflação se situe abaixo da meta em 2020, pois as projeções de consenso mais recentes apontam que, mesmo com a perspectiva de que a taxa Selic recue em cerca de 1,50 p.p. ao longo 
dos próximos meses, o IPCA ainda assim encerraria o próximo ano um pouco abaixo da meta.

Gráfico 10. IPCA e núcleo da inflação, em \% a.a.

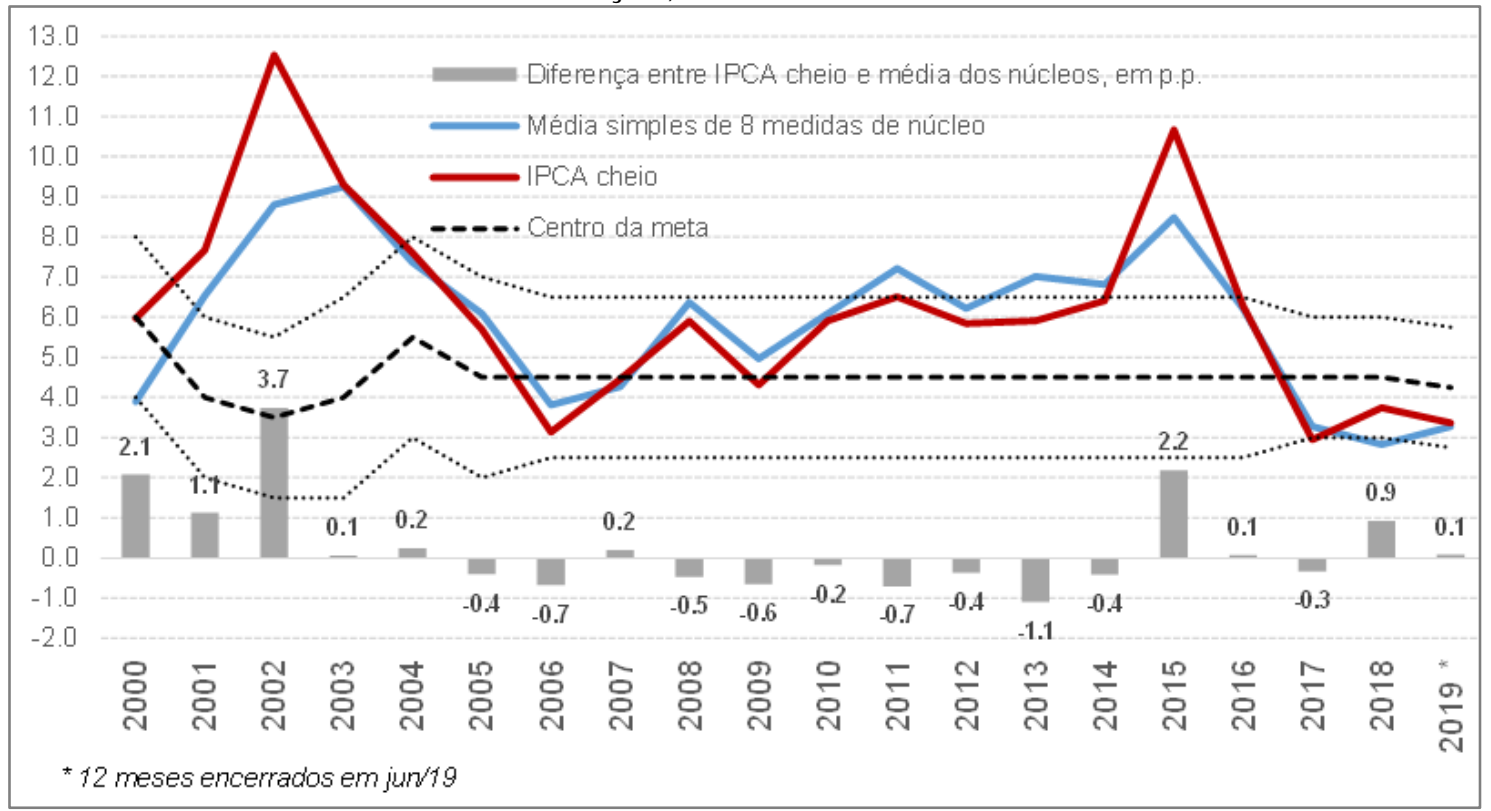

Fonte: BCB e LCA.

O Gráfico 10 também revela que, caso a análise da dinâmica inflacionária seja realizada a partir de uma média simples de 8 medidas de núcleo do IPCA - as quais excluem alguns choques/ruídos pouco correlacionados ao ciclo econômico , fica ainda mais evidente o quadro de excesso de ociosidade bastante elevado dos fatores de produção, na medida em que a inflação subjacente correu mais próxima do piso do intervalo de metas nos últimos 2 anos e meio.

As três constatações apontadas acima - 11 estimativas independentes apontando hiato do produto consideravelmente negativo e se alterando muito pouco nos últimos anos; necessidade de financiamento externa altamente negativa; e inflação persistentemente abaixo da meta - confluem para um mesmo diagnóstico: o principal fator limitante a uma expansão mais rápida do PIB brasileiro nos últimos três anos tem sido a falta de demanda e não uma eventual restrição agregada pelo lado da oferta.

Dado o arcabouço de política econômica vigente no Brasil, as constatações acima também sugerem que a política monetária brasileira não atuou de forma simétrica nos últimos anos - algo que aparentemente foi tolerado por conta de um tratamento assimétrico dado a desvios negativos da inflação em relação à meta (em contraste com os desvios positivos observados durante boa parte do período 20102016). Dito de outro modo: inflação abaixo da meta parece ser preferível do que 
inflação acima da meta, na visão das autoridades e mesmo de vários analistas, sem gerar nenhum tipo de constrangimento "reputacional" para a autoridade monetária.

Contudo, é importante assinalar que, formalmente, o regime de metas de inflação não prevê esse tipo de assimetria de tratamento em relação ao sinal dos desvios da inflação em relação ao objetivo. Os Bancos Centrais que operam sob o regime de metas de inflação devem buscar manter a inflação oscilando em torno da meta (a qual é definida previamente, seguindo uma outra institucionalidade). Desvios positivos ou negativos da inflação em relação à meta em um ano ou outro podem acontecer, sobretudo por conta de choques não antecipados. Mas, quando esses desvios são sistemáticos e relevantes, isso sugere que há problema de calibragem da política monetária (e mesmo da política econômica).

Uma maneira de avaliar a adequação da política monetária praticada pelo Banco Central do Brasil nos últimos anos envolve estimar a função de reação do $\mathrm{BCB}$, nos moldes da regra de Taylor ${ }^{8}$. É sabido que as decisões de política monetária nos países que operam sob o regime de metas de inflação podem ser razoavelmente aproximadas pela regra de Taylor $^{9}$, que estabelece que a taxa básica de juros fixada pelo BC em cada momento do tempo é uma função da taxa de juros "neutra" e de desvios da inflação esperada em relação à meta, bem como de desvios do produto em relação ao potencial (hiato).

Para estimar a regra de Taylor brasileira, foi considerada como uma proxy da Selic nominal neutra a mediana da projeção do consenso de mercado (Focus/BCB) para a própria Selic, mas três anos à frente (ou seja, já além do horizonte típico de atuação da política monetária, entre 12 e 24 meses à frente), apresentada no Gráfico 11.

Para realizar essa estimação, também é necessária alguma medida de hiato do produto. Além de utilizar a média simples das 9 medidas de hiato (Gráfico 7), também foram consideradas outras duas medidas alternativas de posição cíclica da economia, de modo a testar a robustez dos resultados encontrados com a primeira medida de hiato. As alternativas são: i) o desvio do Nível de Utilização da Capacidade Instalada (NUCI) na indústria de transformação em relação à média histórica (FGV); e ii) Índice de Situação Atual da Sondagem de Clima Econômico (FGV/Ifo), que é um indicador de difusão (com leituras entre -100 e +100) construído a partir da percepção de especialistas pesquisados trimestralmente.

${ }^{8}$ Para uma análise similar para a economia norte americana, ver Ball e Tchaidze (2002).

9 O que não significa dizer que a política monetária deve seguir "mecanicamente" essa regra. 
Gráfico 11. Estimativa de taxa de juros neutra (Selic projetada 3 anos à frente), em $\%$ a.a.

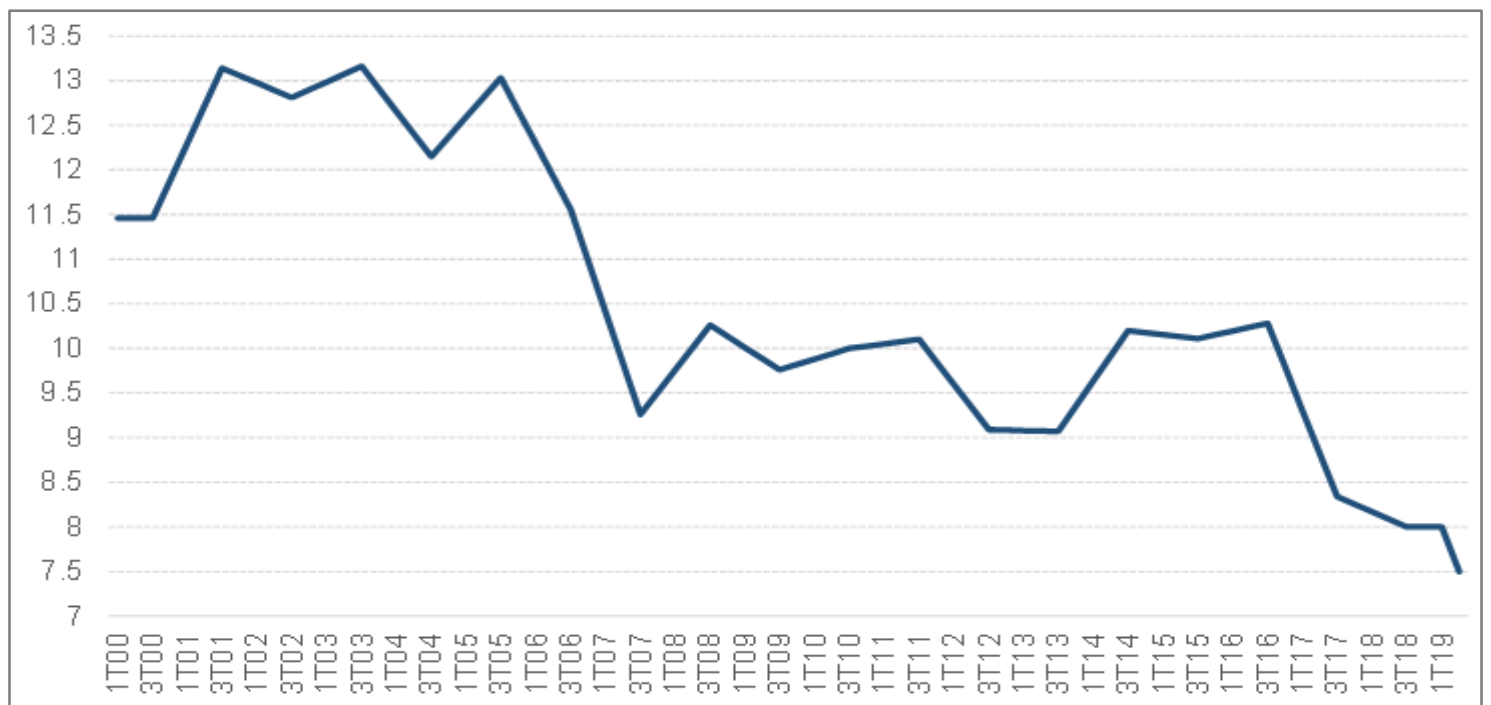

Fonte: $\mathrm{BCB} /$ Focus.

A regra de Taylor foi estimada em bases trimestrais e somente até meados de 2011, já que, entre agosto daquele ano e meados de 2016, a política monetária se comportou de forma distinta do que é preconizado pela regra de Taylor conforme demonstraram Barbosa, Camelo e Joao (2016). Ademais, como o exercício pretende avaliar a adequação da política monetária nos últimos três anos, o período recente também foi excluído da amostra. Vale lembrar que o período 2000-2011, utilizado para estimar a regra de Taylor, correspondeu a um período de elevada credibilidade da política monetária doméstica.

Foram acrescentadas outras duas variáveis explicativas na regra de Taylor estimada: i) variações da razão entre recolhimentos compulsórios e o agregado monetário M2 (já que muitas vezes essas alterações foram utilizadas como complementos/substitutos para a política monetária no Brasil); e ii) o Índice de Condições Financeiras dos EUA calculado pelo Goldman Sachs, de modo a captar o efeito que as condições financeiras internacionais possui sobre a postura da política monetária doméstica, ao afetar prêmios de risco e os preços dos ativos locais.

Os resultados econométricos obtidos a partir do estimador Nonlinear Least Squares ${ }^{10}$, estão sintetizados no Gráfico 12. Entre meados de 2011 e meados de 2019, são apresentadas projeções fora da amostra para a Selic target, considerando

${ }^{10}$ O Nonlinear Least Squares é uma derivação não linear do OLS. Carvalho, Nechio e Tristão (2018) apresentam evidências de que o viés de estimação da regra de Taylor com o estimador OLS é baixo e inferior àquele associado à utilização de variáveis instrumentais (OLS-IV / GMM). 
a evolução efetivamente observada da proxy da Selic neutra, do desvio da inflação esperada 12 meses à frente em relação à meta (Focus/BCB) e do hiato do produto.

Gráfico 12. Trajetórias estimadas para a Taxa Selic Nominal, em \% a.a., fim de período.

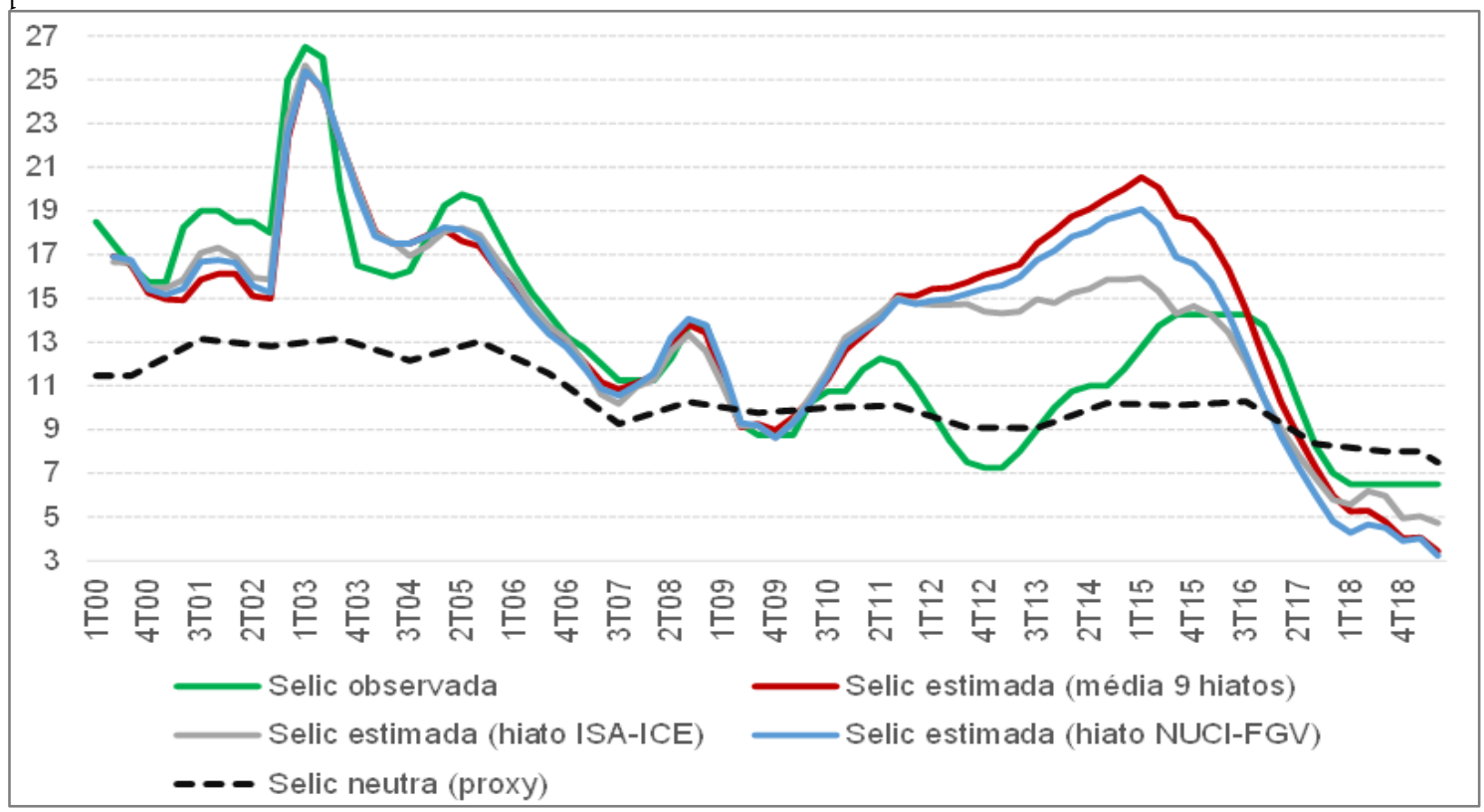

Fonte: Elaboração própria.

Nas três versões estimadas da regra de Taylor, com três medidas alternativas de hiato, esta variável se revelou estatisticamente significante, tendo peso positivo na função de reação do BCB. Portanto, a evidência empírica aponta que o BCB de fato operou sob um regime de flexible inflation targeting entre 2000 e meados de 2011, atuando para suavizar os ciclos econômicos e não negligenciando os custos, em termos da atividade econômica, de sua atuação buscando manter a inflação na trajetória de metas.

Como pode ser notado, todas as estimativas apontam que, de fato, a Selic efetiva se desviou bastante, para baixo, do referencial apontado pela regra de Taylor entre meados de 2011 e meados de 2016. A partir de então, passa a ocorrer algo oposto, com a Selic recuando mais lentamente do que o sugerido pelas estimativas. Essa diferença, por sua vez, passa a se alargar a partir de meados de 2018. Dados o hiato atual e as expectativas de inflação 12 meses à frente, os referenciais das regras estimadas apontam que a taxa Selic deveria ter encerrado o 2T/2019 em algo entre $3,25 \%$ e $4,75 \%$, bem abaixo dos $6,50 \%$ efetivamente observados.

Por fim, o Gráfico 13 compara os desvios da inflação observada em relação à meta e os desvios da Selic efetiva em relação ao referencial sugerido pela Taylor (foi considerada a média simples das 3 regras de Taylor apontadas acima). Como 
pode ser notado, o desvio da Selic efetiva em relação ao referencial da Taylor antecipa, razoavelmente bem, em cerca de 4 trimestres, o desvio da inflação observada em relação à meta. Portanto, o referencial sugerido pela regra de Taylor é informativo do comportamento prospectivo da inflação, em relação à meta, constituindo um bom indicador para avaliar a política monetária. $\mathrm{O}$ exercício numérico ajuda a referendar nossas conclusões sobre o comportamento atual da política monetária.

Gráfico 13. Desvio da Selic em relação ao sugerido pela regra de Taylor vs Desvio do IPCA observado em relação à meta (em p.p.)

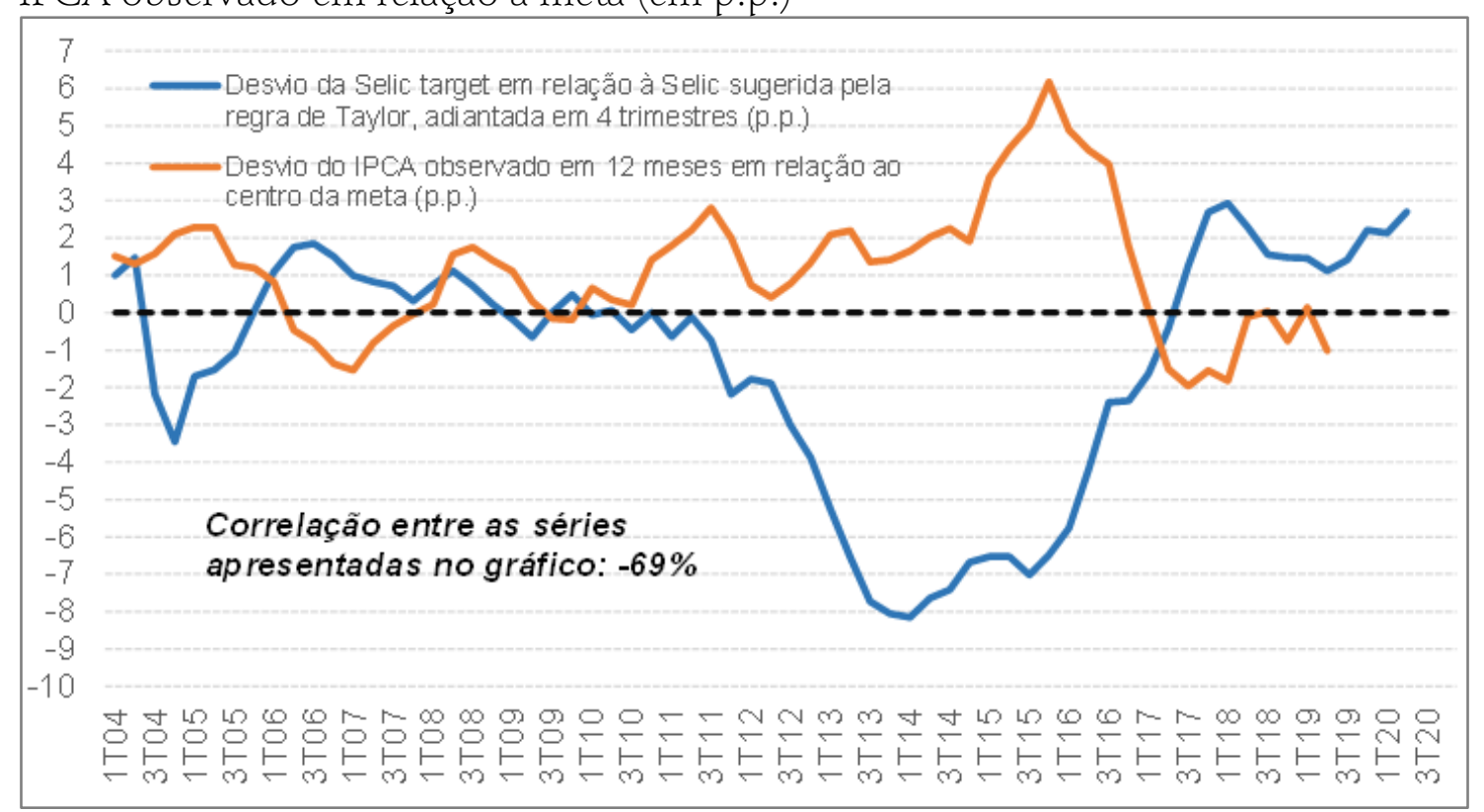

Fonte: Elaboração própria.

Em suma, existem várias evidências de que a postura da política monetária doméstica tem sido inadequada desde meados de 2016, sobretudo desde meados de 2018. Em função das mudanças estruturais no mix de política econômica ocorridas desde 2016, com a introdução do teto de gastos para o governo federal e com a contenção acentuada do crédito público, as políticas fiscal e parafiscal deixaram de ser altamente expansionistas, passando a ter uma postura mais neutra/contracionista. Portanto, nesse novo arranjo macroeconômico, fica à cargo da política monetária a administração do ciclo econômico, estando sujeito, obviamente, à restrição da meta inflacionária.

Embora $\mathrm{O}$ BCB aponte que a política monetária já esteja em terreno estimulativo desde o final de 2017, o fato é que há diversos indicadores na economia - baixo déficit em conta corrente, inflação abaixo das metas, expectativas inflacionárias abaixo das metas no horizonte relevante de política monetária, 
ociosidade em diversos segmentos da economia, desemprego elevado etc. - que apontam que a magnitude do impulso monetário tem sido insuficiente.

\section{Consequências para a formulação da política econômica}

Vários trabalhos vêm questionando cada vez mais a hipótese de que os ciclos econômicos de curto prazo não afetam os níveis de longo prazo do PIB e da taxa de desemprego, levando a academia a buscar novas explicações para avaliar o desempenho macroeconômico dos países em prazos mais dilatados. Como resultado, surgem novas prescrições de política econômica.

Walentin e Westermark (2018) fizeram uma revisão bibliográfica dos trabalhos conceituais e empíricos questionando essa premissa. Como apontam os autores, esse questionamento se inicia com os trabalhos de Blanchard e Summers (1986) e DeLong e Summers (1988), ganhando bastante corpo após a grande crise financeira de 2008/09. São vários os canais que atuam para transmitir os efeitos das oscilações cíclicas sobre o PIB potencial, mas Blanchard (2017) aponta que o principal deles parece ser o fenômeno da histerese no mercado de trabalho, associado à dinâmica de acumulação de capital humano ao longo da vida laboral. Dentre os demais canais, podem ser elencados os fenômenos da "fuga de cérebros", redução das taxas de fertilidade, aumento da obsolescência do estoque de capital e aumento persistente do prêmio de risco cobrado pelos investidores após perdas severas em crises econômicas profundas e prolongadas.

O exercício cujos resultados são apresentados a seguir, combinam equações econométricas estimadas para a taxa de desemprego de equilíbrio (NAWRU/NAIRU), para a produtividade total dos fatores e para a taxa de investimento (levando em conta vários condicionantes estruturais/institucionais e conjunturais dessas variáveis), no âmbito de uma função de produção para a economia brasileira a la modelo de Solow. Aponta, ainda, os efeitos estimados, ao longo do tempo, da demora em exaurir o excesso de ociosidade da economia.

O Gráfico 14 apresenta os impactos, sobre o nível da Formação Bruta de Capital Fixo, de um choque que levaria o nível de utilização da capacidade instalada na indústria de transformação (um dos condicionantes conjunturais dos investimentos em ativos fixos) dos atuais $75 \%$ para pouco mais de $80 \%$ (média histórica), imediatamente e permanentemente, a partir do 3T/2019. No cenário de referência utilizado para realizar essa comparação, o nível de utilização subiria gradativamente até atingir a média histórica somente no começo de 2023. 
Gráfico 14. Impacto sobre o nível da FBCF de um choque permanente no NUCI no período $\mathrm{T}$

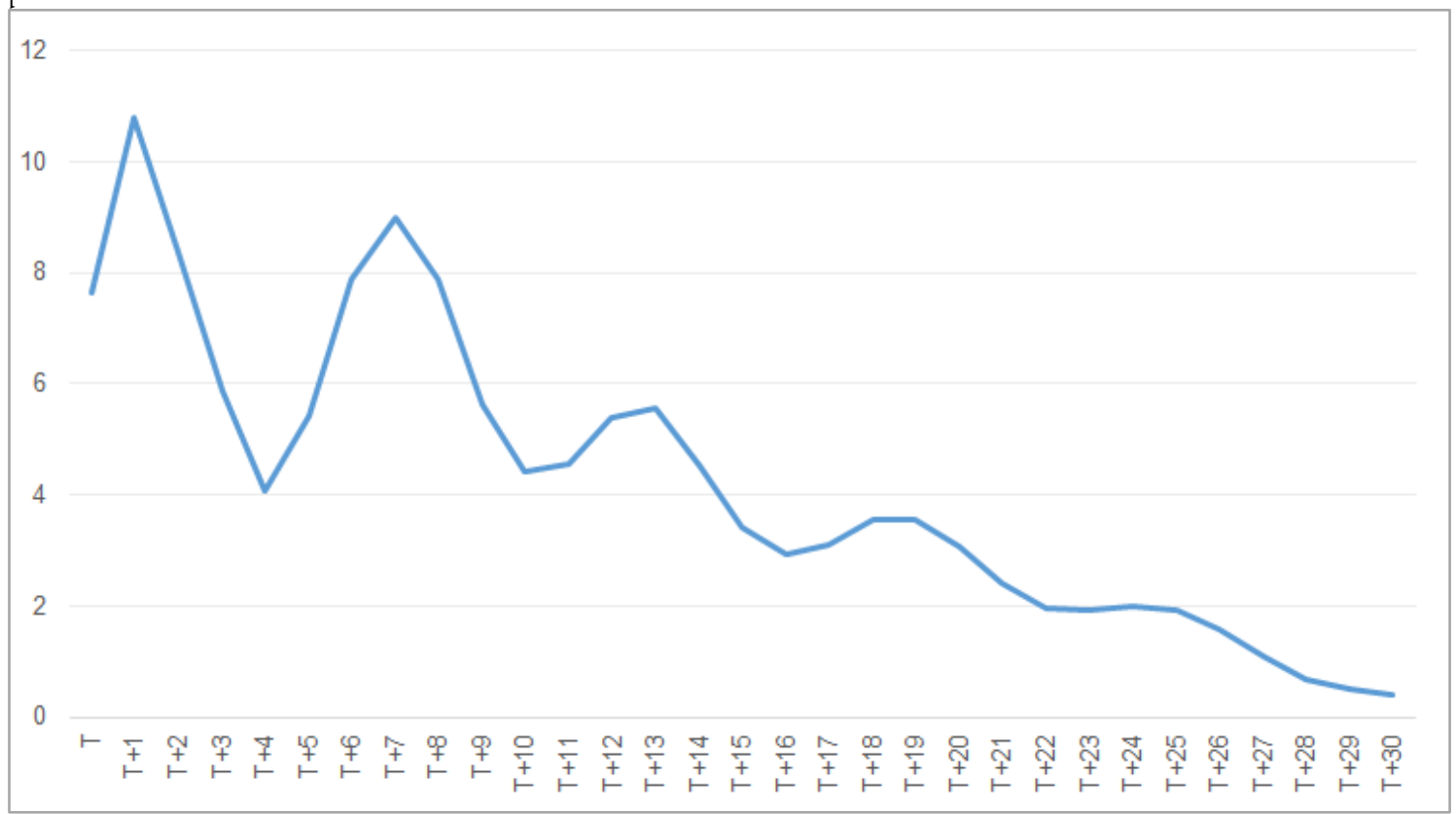

Fonte: Elaboração própria. Nota: Choque eleva o nível de FBCF imediatamente para a média histórica de 80,3\%, comparativamente a um cenário base em que essa convergência ocorreria somente em $\mathrm{T}+14$.

Como pode ser notado, uma elevação imediata do NUCI em cerca de 5 p.p. elevaria a FBCF em $8 \%$ imediatamente e em quase $11 \%$ dois trimestres à frente (em relação a um cenário base em que o NUCI convergiria para a média histórica até o 1T23). O gráfico aponta que, embora não permanentes, os efeitos desse choque simulado são bastante persistentes, já que um investimento maior leva a mais PIB potencial por vários canais (aumento do estoque de capital; redução da idade média do estoque de capital afetando positivamente a produtividade sistêmica; redução da taxa de desemprego estrutural via elevação da relação capital / PEA) e mais PIB potencial leva a mais FBCF em um segundo momento (elevação da renda permanente), gerando um "círculo virtuoso" bastante duradouro.

No Gráfico 15 são apresentados os impactos estimados, desse mesmo choque no NUCI, sobre o PIB efetivo e o PIB potencial (também em relação ao cenário de referência descrito acima, caracterizado por um fechamento do hiato do NUCI somente no começo de 2023). Como pode ser notado, há um impacto permanente (ao menos no horizonte de quase uma década) e positivo desse choque, ilustrando claramente os efeitos que a histerese pode ter sobre as perspectivas para economia brasileira nos próximos anos. Vale notar que o arcabouço utilizado para realizar essas simulações somente capta a histerese via quantidade e idade média do estoque de capital. Caso sejam agregados também os 
efeitos via estoque de capital humano e oferta de mão-de-obra, os efeitos são potencialmente maiores.

Gráfico 15. Impacto sobre o nível do PIB efetivo/potencial de um choque permanente no NUCI no período T

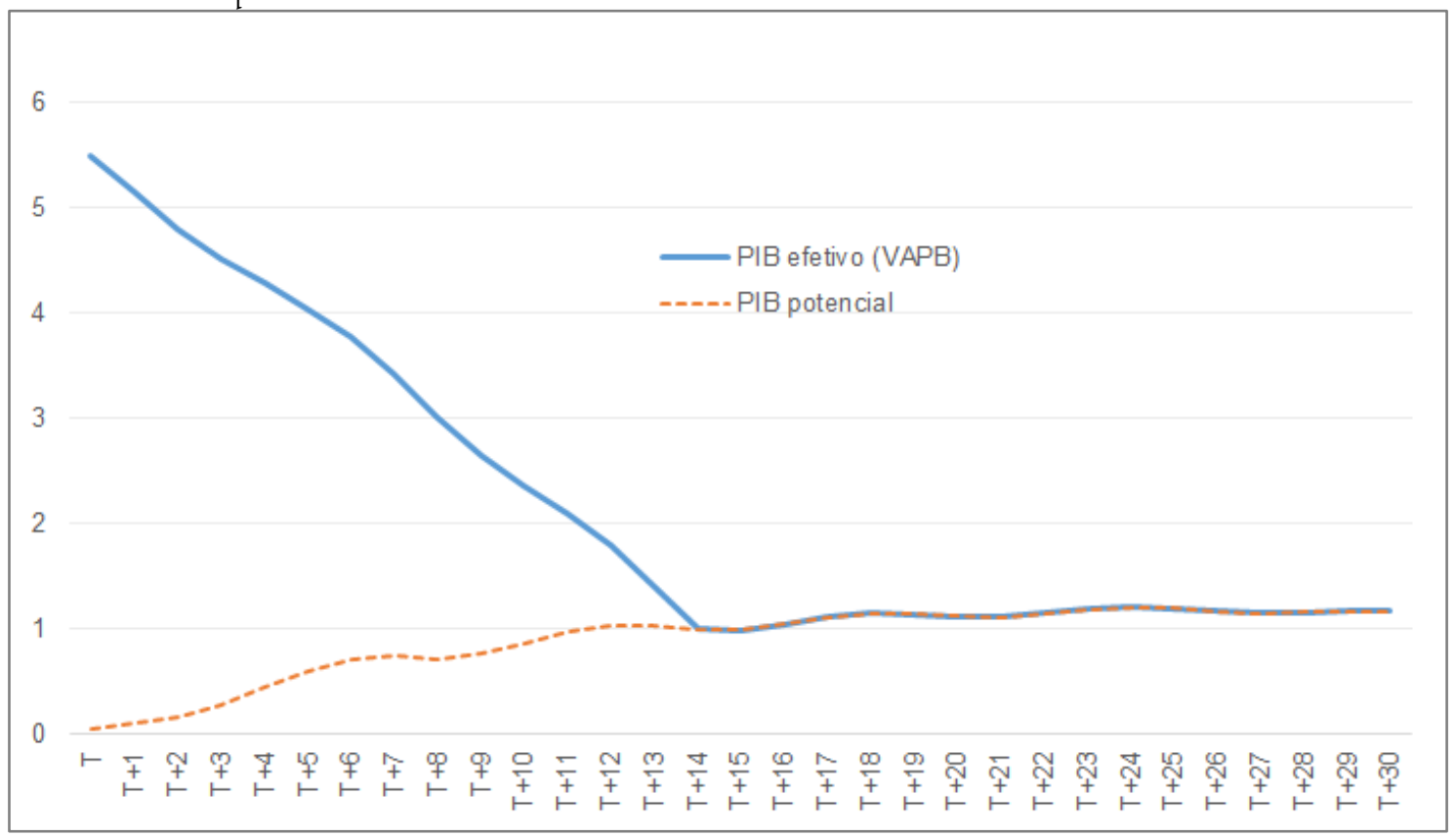

Fonte: Elaboração própria. Nota: Choque leva o PIB efetivo/potencial imediatamente para a média histórica de 80,3\%, comparativamente a um cenário base em que essa convergência ocorreria somente em $\mathrm{T}+14$.

Portanto, um bom gerenciamento dos ciclos econômicos também produz impactos de médio e longo prazo positivos, em contraste com a visão (ainda) dominante. Com efeito, além de reforçar a sugestão de que a "suavização do ciclo econômico" passe a integrar o mandato formal da política monetária brasileira (além da inflação e da estabilidade financeira), essa constatação também indica que os arranjos de política tributária e de gastos do governo também deveriam ser desenhados de modo a criar alguns estabilizadores automáticos dos ciclos econômicos. Alternativas como a adoção de metas de resultado primário estrutural ou de metas medidas ao longo de um conjunto de anos, para além do anocalendário, combinada a um teto de gastos mais flexível e que exclua os gastos com alguns investimentos públicos, atuariam nesse sentido.

Nesse contexto, os custos econômicos e sociais de se negligenciar políticas de gestão da demanda em uma economia operando bastante aquém do plenoemprego ${ }^{11}$ não se limitam ao curto prazo, podendo se estender para o médio e longo

\footnotetext{
${ }^{11}$ Houve um abuso na utilização dessas políticas entre 2011 e 2014, com uma atuação claramente prócíclica da política econômica em uma economia que vinha operando próxima do pleno-emprego. Isso levou a uma situação de hiperemprego em 2014, mas ao custo de um déficit em conta corrente de
} 
prazo. Não somente pela questão da histerese, mas também por conta do processo de consolidação fiscal: aproximadamente metade do ajuste fiscal necessário para restaurar a solvência fiscal intertemporal brasileira, de cerca de 4 p.p. do PIB, é conjuntural - e a outra metade, estrutural (demandando, neste último caso, reformas nos gastos obrigatórios e/ou mudanças na carga tributária). Em outras palavras, o hiato do produto altamente negativo no momento atual está subtraindo cerca de 2 p.p. do PIB da arrecadação recorrente e do resultado primário do governo geral, adiando a estabilização e mesmo a inflexão da relação DBGG/PIB ${ }^{12}$.

Ao menosprezar o quadro de persistente e elevado subemprego presente na economia brasileira, a política econômica deturpa a lógica da recuperação cíclica porque tende a fazer com que parte do fechamento do hiato de recursos se dê por meio de uma redução do potencial, ao invés de se concentrar em restabelecer o PIB corrente.

Como apontado na seção anterior, a política monetária tem sido inapropriada nos últimos anos. Uma adequação dessa política, além de impulsionar a economia, teria como efeitos colaterais benéficos uma redução dos encargos da dívida pública, criando espaço para um círculo virtuoso com potencial de duração bastante longo, caso a agenda de reformas prossiga avançando.

A mudança de um regime de juros altos para um regime de juros baixos também precisa ser acompanhada de reformas que maximizem seus efeitos sobre a economia como um todo. Isso requer uma agenda mais ativa na redução dos spreads bancários, reorientação da atuação do crédito público - que deve ser alocado com taxas de juros mais alinhadas às taxas flutuantes da economia - e maior foco na concessão de garantias do que em operações com taxas favorecidas.

Algum estímulo fiscal também deveria ser empregado, reconhecendo que uma política fiscal expansionista só produzirá os efeitos esperados caso seja percebida como sustentável do ponto de vista da solvência intertemporal do governo. Por isso é importante que ela se concentre nos investimentos mais simples de serem retomados e em projetos de elevado retorno econômico e social, e que não se perca de perspectiva o papel de reformas fiscais que possam corrigir a trajetória de longo prazo da dívida pública.

quase $5 \%$ do PIB e de uma forte deterioração fiscal. Contudo, hoje a posição cíclica da economia brasileira justifica políticas de estímulo à demanda - e o comportamento do PIB, das contas externas e da inflação (em relação à meta) indicam que essas políticas têm sido claramente insuficientes.

${ }^{12}$ Ver, por exemplo, Borges (2019). 
Do ponto de vista setorial, os dados deixam bastante evidente que a principal sequela da crise atual está no setor de construção civil, que continua em recessão. Parte desse segmento não se beneficiou da queda das taxas de juros porque suas taxas são fixas. A queda dos investimentos do setor público também produziu grande impacto porque são concentrados em construção civil. A agenda de privatizações, no curto prazo, não estimula investimentos porque seu resultado é a troca de propriedade de ativos já constituídos e a agenda de concessões historicamente tem uma velocidade própria. Nesse contexto, medidas mais pontuais, direcionadas a esse setor, também deveriam ser avaliadas - até mesmo por conta do forte impacto que ele exerce sobre o mercado de trabalho.

\section{Conclusões}

A economia brasileira sofreu uma das recessões mais profundas e longevas de sua história. Passados exatos cinco anos do início do processo de contração da economia, e dois anos do final da recessão, a economia ainda encontra-se mais de $5 \%$ abaixo de seu patamar vigente previamente. Relativamente à média dos nove episódios de contração da economia desde 1980 datados pelo CODACE, a atividade econômica está 12,4\% em patamar inferior. Essa dinâmica guarda relação com a intensidade da crise enfrentada pelos países da periferia da Zona do Euro, e é bem mais pronunciada do que a recessão norte-americana no âmbito do colapso financeiro global de 2008/09. Em termos de PIB per capita, a década de 2011-2020 terá uma taxa de crescimento média próxima de zero.

Um dos aspectos mais marcantes desse processo está na mudança do arranjo de política macroeconômica implementado na economia brasileira em 2015/2016. A introdução do novo regime fiscal - ancorado no teto de gastos - associado à contração do crédito público (parafiscal) gera uma redução significativa no nível da demanda agregada da economia. Nesse novo contexto, a política monetária passa a ter um papel fundamental, pois se torna o principal instrumento de administração do ciclo econômico de curto prazo, sujeito, obviamente, aos limites do regime de metas inflacionárias. É claro que a taxa de juros nominal brasileira caiu de maneira significativa no passado recente, porém não na magnitude necessária para recuperação cíclica da economia.

Há diversas estimativas que apontam que o hiato do produto da economia brasileira é bastante negativo. No entanto, por se tratar de uma variável não observável, sua estimativa está sujeita a uma gama significativa de incertezas. Uma maneira mais concreta da evidência do profundo déficit atual de demanda agregada 
da economia brasileira é o comportamento de algumas variáveis observáveis. Nesse aspecto, há um amplo cardápio disponível: i) inflação sistematicamente abaixo das metas desde 2017; ii) expectativas inflacionárias cadentes e abaixo da meta; iii) as medidas de inflação mais sensíveis ao ciclo econômico - inflação de serviços e núcleos - permanecem em níveis muito baixos; iv) ampla ociosidade em diversos setores da economia - indústria, serviços e construção; v) taxa de desemprego e medidas ampliadas de mercado de trabalho ainda em patamares muito elevados; vi) posição confortável do saldo do balanço de pagamentos em transações correntes.

Uma das consequências mais graves de uma recuperação cíclica muito demorada são seus impactos na tendência de crescimento de longo prazo da economia. Tal fenômeno é conhecido na literatura como histerese, e as evidências apontam efeitos substantivos na deterioração do mercado de trabalho. A manutenção de um tempo prolongado em situação de desemprego faz com que os trabalhadores percam habilidades laborais ao longo do tempo, afetando a dinâmica de acumulação de capital humano, e tornando ainda mais difícil sua recolocação no mercado de trabalho. Esse processo tende a afetar o crescimento potencial de longo prazo.

Portanto, adoção de políticas que estimulem a economia pelo lado da demanda agregada é de fundamental importância para o fechamento do hiato do produto e para a aceleração do crescimento econômico no curto prazo. Tal ponto, naturalmente, não é incompatível com a adoção de reformas econômicas que tenham a intenção de tornar a economia brasileira mais eficiente e produtiva. São agendas complementares e que devem ser endereçadas de maneira simultânea. Uma característica essencial para os gestores da política econômica é que o pragmatismo deve, em qualquer situação, prevalecer sobre qualquer visão de mundo e a ideologia.

\section{Referências}

Ball, L. \& Tchaidze, R. (2002). The FED and the new economy. American Economic Review, 92(2), 108-114. doi: 10.1257/000282802320189096.

Barbosa, F., Camelo, F. \& Joao, I. (2016). A taxa de juros natural e a regra de Taylor: 2003-2015. Revista Brasileira de Economia, 70(4), 399-417. doi: 10.5935/0034-7140.20160021.

Barboza, R. (2019). A década frustrada. Jornal Valor Econômico. Disponível em $<$ https://www.valor.com.br/opiniao/6205137/decada-frustrada> 
BCB - Banco Central Brasil (2019). Relatório de Inflação, 21(2), 1-59, Brasília: Banco Central do Brasil. Disponível em: <https://www.bcb.gov.br/ content/publicacoes/ri/201906/ri201906p.pdf>

Blanchard, O. (2017). Should we get rid of the Natural Rate Hypothesis? NBER Working Paper, 24057, National Bureau of Economic Research, Cambridge, MA. doi: 10.3386/w24057.

Blanchard, O. \& Summers, L. (1986). Hysteresis and European unemployment problem. In: Fischer, S. NBER Macroeconomics Annual, v.1. National Bureau of Economic Research, Cambridge, MA.

Borges, B. (2019). Resultado fiscal estrutural brasileiro encerrou 2018 em terreno ligeiramente positivo, pela primeira vez desde 2012. Blog do Ibre. Disponível em <https://blogdoibre.fgv.br/posts/resultado-fiscal-estruturalbrasileiro-encerrou-2018-em-terreno-ligeiramente-positivo-pela>

Borça Jr., G., Barboza, R. \& Furtado, M. (2019). A recuperação do PIB brasileiro em recessões: uma visão comparativa. Blog do Ibre. Disponível em $<$ https://blogdoibre.fgv.br/posts/recuperacao-do-pib-brasileiro-emrecessoes-uma-visao-comparativa>

Braga, J. \& Lara, F. (2019). De onde virá a demanda que justificará a recuperação do investimento? Excedente, Grupo de Economia Política da UFRJ. Disponível em: $\quad<$ http://www.excedente.org/blog/de-onde-vira-a-demanda-quejustificara-a-recuperacao-do-investimento/>

Carvalho, C., Nechio, F. \& Tristão, T. (2018). Taylor rule estimation by OLS. Federal Reserve Bank of San Franscisco Working Paper, 2018-11, 1-39. doi: 10.24148/wp2018-11.

CODACE (2017). Comitê de Datação de Ciclos Econômicos. FGV: São Paulo. Disponível em $<$ https://portalibre.fgv.br/data/files/F3/C1/F8/E8/A18F66108DDC4E66C A

18B7A8/Comite\%20de\%20Data_o\%20de\%20Ciclos\%20Econ_micos\% 20-\%20Comunicado\%20de\%2030_10_2017\%20_1_.pdf >

DeLong, B. \& Summers, L. (1988). How does macroeconomic policy affect output? Brooking Papers on Economic Activity, Brookings Institution, 2, 433-494. 
International Monetary Fund (2019). Article IV Consultation Press Release, Staff Report and statement by the executive director for Brazil, IMF Country Report, 19/242, 1-14, Washington, DC: IMF.

Khan, L. (2010). The long-term labor market consequences of graduating from college in a bad economy. Labour Economics, 17(2), 303-316.

Montero, P. (2019). PIB per capita caminha para ter variação zero na década. Valor Econômico, p. A5. Disponível em: <https://glo.bo/2kODKgU>

Pastore, A., Pinotti, M., Gazzano, M. \& Magalhães, P. (2019). A Depressão Depois da Recessão. Informe Especial A.C. Pastore Associados.

Phelps, E. (1972). Inflation Policy and Unemployment Theory. New York: Norton.

Walentin, K. \& Westermark, A. (2018). Learning on the job and the cost of business cycle. Sveriges Riskbank Working Paper, 353, Sveriges Riskbank, Estocolmo. Disponível em $<$ https://www.riksbank.se/globalassets/media/rapporter/ working-papers/2018/no.-353-learning-on-the-job-and-the-cost-ofbusiness-cycles>

Secretaria de Política Econômica - Ministério da Economia (2019). Boletim Resultado Fiscal Estrutural - 2018. Brasília: SPE.

Williams, J. (2013). Lessons from the Financial Crisis for Unconventional Monetary Policy. Panel discussion at the NBER Conference. Disponivel em $<$ https://www.frbsf.org/our-district/files/Williams-Lessons-from-theFinancial-Crisis-for-Unconventional-Monetary-Policy.pdf> 